\title{
Growth hormone enhances thymic function in HIV-1-infected adults
}

\author{
Laura A. Napolitano, ${ }^{1,2}$ Diane Schmidt, ${ }^{2}$ Michael B. Gotway, ${ }^{3}$ Niloufar Ameli, ${ }^{4}$ \\ Erin L. Filbert, ${ }^{1}$ Myra M. Ng, ${ }^{1}$ Julie L. Clor, ${ }^{1}$ Lorrie Epling, ${ }^{2}$ Elizabeth Sinclair, ${ }^{2}$ \\ Paul D. Baum, ${ }^{2}$ Kai Li, ${ }^{1}$ Marisela Lua Killian, ${ }^{2}$ Peter Bacchetti, ${ }^{5}$ and Joseph M. McCune ${ }^{2}$ \\ ${ }^{1}$ Gladstone Institute of Virology and Immunology, San Francisco, California, USA. ${ }^{2}$ Department of Medicine and \\ ${ }^{3}$ Department of Radiology, San Francisco General Hospital and UCSF, San Francisco, California, USA. \\ ${ }^{4}$ Department of Medicine and 5Department of Epidemiology and Biostatistics, UCSF, San Francisco, California, USA.
}

\begin{abstract}
Growth hormone (GH) is an underappreciated but important regulator of T cell development that can reverse age-related declines in thymopoiesis in rodents. Here, we report findings of a prospective randomized study examining the effects of GH on the immune system of HIV-1-infected adults. GH treatment was associated with increased thymic mass. In addition, GH treatment enhanced thymic output, as measured by both the frequency of $T$ cell receptor rearrangement excision circles in circulating $T$ cells and the numbers of circulating naive and total $\mathrm{CD}^{+} \mathrm{T}$ cells. These findings provide compelling evidence that $\mathrm{GH}$ induces de novo $\mathrm{T}$ cell production and may, accordingly, facilitate $\mathrm{CD} 4^{+} \mathrm{T}$ cell recovery in $\mathrm{HIV}$-1-infected adults. Further, these randomized, prospective data have shown that thymic involution can be pharmacologically reversed in humans, suggesting that immune-based therapies could be used to enhance thymopoiesis in immunodeficient individuals.
\end{abstract}

\section{Introduction}

Infection with HIV-1 is frequently characterized by $\mathrm{T}$ cell loss and an increased risk of illness or death from infection. Upon provision of effective antiretroviral therapy (ARV), many patients experience a rapid decrease in circulating viral load and an increase in circulating $\mathrm{CD}^{+} \mathrm{CD}^{+} \mathrm{T}$ cells (herein referred to as $\mathrm{CD} 4^{+} \mathrm{T}$ cells). Nevertheless, a considerable number of individuals retain persistent quantitative and qualitative immune defects despite ARV treatment (1-6). In $10 \%-15 \%$ of ARV recipients, decreases in viral load are not associated with substantial gains in the $\mathrm{CD} 4^{+} \mathrm{T}$ cell count. Likewise, an increase in the $\mathrm{CD} 4^{+} \mathrm{T}$ cell count is not always associated with reconstitution of a fully diverse TCR repertoire, and despite successful treatment with ARV, "holes" in the TCR repertoire may facilitate the persistence of infection with opportunistic pathogens or HIV-1 (1, 7-10).

The thymus is the primary site of de novo $\mathrm{T}$ cell production, and its function may be a pivotal factor in determining the potential for $T$ cell recovery in immunodeficient individuals. Although the thymus was once thought to be active only early in life, a thymic reserve appears to persist into adulthood $(11,12)$, and its function may increase in the setting of lymphopenia induced by chemotherapy $(13,14)$ or HIV-1 disease $(15)$. Studies of T cell reconstitution after lymphopenia demonstrate that a greater abundance of thymic tissue is associated with improved recovery of total and naive $\mathrm{CD}^{+} \mathrm{T}$ cells $(2,16-20)$, increased frequency of TCR rearrangement excision circles (TRECs) $(11,21,22)$, and increased TCR repertoire diversity $(21,23)$. Thus, therapeutic agents that stimulate thymic function may improve the quantity and quality of immune reconstitution during HIV-1 infection.

Nonstandard abbreviations used: AE, adverse event; ARV, antiretroviral therapy; DR, HLA-DR; GH, growth hormone; HU, Hounsfield unit(s); NCD4 cell, naive $\mathrm{CD}^{+}{ }^{+} \mathrm{CD} 4{ }^{+} \mathrm{CD} 45 \mathrm{RA}^{+} \mathrm{CD} 62 \mathrm{~L}^{+} \mathrm{T}$ cell; $\mathrm{NCD} 8$ cell, naive $\mathrm{CD} 3{ }^{+} \mathrm{CD} 8{ }^{+} \mathrm{CD} 45 \mathrm{RA}^{+} \mathrm{CD} 62 \mathrm{~L}^{+}$ T cell; RTE, recent thymic emigrant; SFGH, San Francisco General Hospital; TNCD8

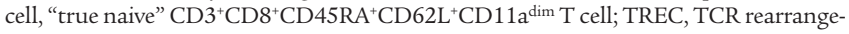
ment excision circle.

Conflict of interest: The authors have declared that no conflict of interest exists. Citation for this article: J. Clin. Invest. 118:1085-1098 (2008). doi:10.1172/JCI32830.
Growth hormone (GH) and its proximal mediator, IGF-1, are important in mammalian thymopoiesis (24). Administration of GH or IGF-1 reverses thymic involution and enhances thymopoiesis in aged rodents (25-27) and accelerates immune reconstitution in immunodeficient animals $(28,29)$. Previously, we hypothesized that therapies to enhance human thymopoiesis might facilitate immune restoration in $\mathrm{HIV}-1$ disease. Based on findings from animal studies, we examined the effects of GH on the thymus of 5 HIV-1infected adults receiving GH as part of a lipodystrophy study (30) and found promising evidence of enhanced thymic function (31). However, interpretation of these findings was limited considerably by the small number of participants and the absence of an internal control arm. Also, because participants were recruited for the presence of HIV-1 lipodystrophy, a condition known to be associated with GH deficiency (32), it is possible that response to $\mathrm{GH}$ was based upon underlying endocrinologic derangement. We now report findings of a prospective randomized study designed specifically to assess GH effects on thymopoiesis in HIV-1-infected adults with persistently low $\mathrm{CD} 4^{+} \mathrm{T}$ cell counts despite virologic suppression with effective ARV.

\section{Results}

Study design and participants. Twenty-two HIV-1-infected adults were enrolled in a randomized, prospective, open-label study of GH treatment (Figure 1). Median baseline values included: age, 50.3 years; $\mathrm{CD}^{+} \mathrm{T}$ cell count, 227 cells/ $\mu \mathrm{l}$; and duration of stable ARV therapy, 2.7 years. Viral load was undetectable in all but 2 individuals (633 and 272 copies/ml). At baseline, patients in the 2 arms did not differ in age; duration of stable ARV; viral load; thymic mass; percentage or absolute counts of total, naive, or activated $\mathrm{CD}^{+} \mathrm{T}$ cells or $\mathrm{CD}^{+} \mathrm{CD}^{+} \mathrm{T}$ cells (herein referred to as $\mathrm{CD}^{+}$ $\mathrm{T}$ cells); or circulating levels of IGF-1 or IL-7 (Table 1).

Effects of GH were measured in 2 ways. First, changes from baseline during the first year were compared in the GH and observational control arms. Second, regression analyses were performed using data from all time points, including data from observational 

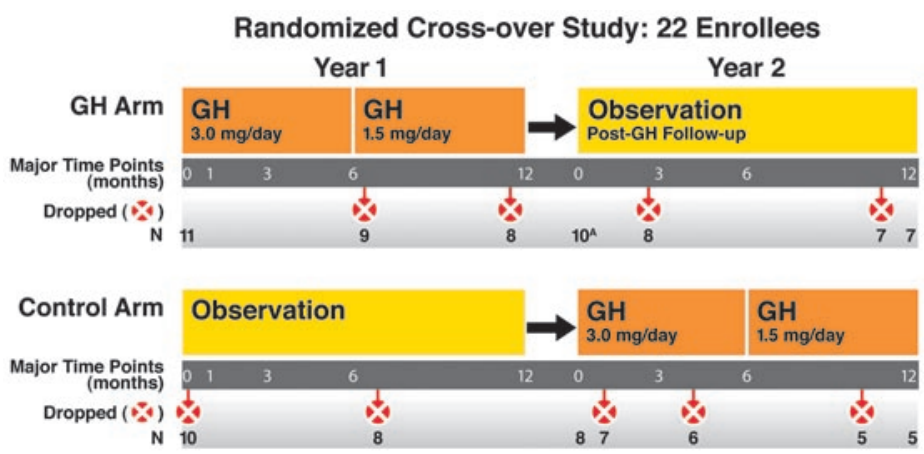

Figure 1

Study design: prospective, randomized, open-label crossover study. The twoyear study design is depicted. Eleven participants each were randomized either to receive GH for 1 year (3.0 mg GH subcutaneous injection daily for 6 months, then $1.5 \mathrm{mg}$ daily for 6 months) while continuing their usual ARV (GH Arm); or to continue usual ARV for 1 year and then cross over to GH treatment and ARV in the second year (Control Arm). Unscheduled changes in GH treatment (premature dose reduction, temporary interruption, or permanent discontinuation) were made by the study investigators as indicated for management of AEs. Major time points, number of participants, and details of dropped participant data from the indicated arm are shown. Additional details of study design and data exclusion can be found in Methods. ATwo GH arm participants who terminated GH early (after month 6) were followed for 1 year after $\mathrm{GH}$. These data are included in 1-year-post-GH follow-up.

controls who crossed over to receive GH in the second year. Unlike the changes-from-baseline analysis, this analysis accounted for early dose reduction or discontinuation of GH.

GH treatment is associated with increased thymic mass and frequency of TRECs. CT scans of the thymus, obtained at baseline and at 6 and 12 months, were analyzed by a thoracic radiologist who performed quantitative computer-based analysis to calculate thymic volume and density (Supplemental Figure 1; supplemental material available online with this article; doi:10.1172/JCI32830DS1). At baseline, all participants had thymic involution with Hounsfield unit (HU) density measurements indicative of replacement of the thymus by adipose tissue (Figure 2 and Table 1). At 6 months, dense tissue appeared prominently in $\mathrm{GH}$ recipients, consistent with cellular thymus (Figure 2, A and B, far-right column). Thymic density increased significantly in the GH arm, compared with that in observational controls, as shown by changes-from-baseline analysis ( +50 HU versus $+1.0 \mathrm{HU} ; P=0.0005)$ (Figure $3 \mathrm{~A}$ and Table $2)$. Comprehensive regression analysis confirmed strong effects of GH treatment on thymic density (41.0 HU higher versus no GH; $P<0.0001$ ) (Figure 3C, left, and Table 3).

To determine whether increased thymic density reflected enhanced thymopoiesis, we measured TRECs within PBMCs, naive $\mathrm{CD}^{+} \mathrm{CD}^{+}{ }^{+} \mathrm{CD} 45 \mathrm{RA}{ }^{+} \mathrm{CD} 62 \mathrm{~L}^{+} \mathrm{T}$ cells (NCD4 cells), and naive $\mathrm{CD}^{+}{ }^{+} \mathrm{CD} 8{ }^{+} \mathrm{CD} 45 \mathrm{RA}^{+} \mathrm{CD} 62 \mathrm{~L}^{+} \mathrm{T}$ cells (NCD8 cells) $\mathrm{T}$ cells. At 6 months, the frequency of PBMC TRECs was $39 \%$ higher in the GH arm and 2.2\% lower in observational controls $(P=0.068)$, as shown by changes-from-baseline analysis. This difference persisted at 12 months but was not statistically significant (Figure 3B and Table 2 ). Comprehensive regression analysis, including crossover $\mathrm{GH}$ treatment of observational controls, demonstrated a $102 \%$ increase in the frequency of PBMC TRECs over 12 months of GH treatment $(P=0.007$ versus no GH) (Figure $3 \mathrm{C}$, right, and Table 3$)$. Although changes-from-baseline analysis also showed that the frequency of
NCD4 TRECs was increased after 6 and 12 months of GH therapy (Table 2), this difference was not statistically significant. Moreover, comprehensive regression analysis showed no increase in naive $\mathrm{T}$ cell TREC frequency. In fact, these regression models estimated that 1 year of $\mathrm{GH}$ treatment was associated with a modest decrease in TREC frequency within circulating naive T cells (Table 3 ). While GH-associated increases in thymic density and PBMC TREC frequency strongly suggested enhanced thymopoiesis, the discordant results of unchanged naive T cell TREC frequency were unexpected and led us to consider the possibility that GH treatment might alter naive $T$ cell TREC content through effects on the peripheral compartment, such as changes in naive $\mathrm{T}$ cell expansion or trafficking.

GH treatment is associated with increased numbers of circulating $\mathrm{CD}^{+}$T cells. CD $45 \mathrm{RA}^{+} \mathrm{CD} 62 \mathrm{~L}^{+}$or CD $45 \mathrm{RA}^{+} \mathrm{CD} 62 \mathrm{~L}^{+} \mathrm{CD} 11 \mathrm{a}^{\text {dim }}$ naive $\mathrm{T}$ cells were identified by immunostaining and flow cytometry. As shown in Figure 4A, the inclusion of memory cell integrin CD11a as a phenotypic marker identified a population of $\mathrm{CD} 45 \mathrm{RA}^{+} \mathrm{CD} 62 \mathrm{~L}^{+}$cells that was also CD11 $\mathrm{a}^{\text {bright }}$ and thus not truly naive (33-35). These non-naive CD11a $\mathrm{a}^{\text {bright }}$ cells were particularly common among $\mathrm{CD}^{+} \mathrm{CD}^{2} 4 \mathrm{RA}^{+} \mathrm{CD} 2 \mathrm{~L}^{+}$cells (median $22.0 \%$ of $\mathrm{CD}^{+} \mathrm{CD} 45 \mathrm{RA}^{+} \mathrm{CD} 62 \mathrm{~L}^{+}$cells in baseline specimens) and less common among $\mathrm{CD} 4^{+} \mathrm{CD} 45 \mathrm{RA}^{+} \mathrm{CD} 62 \mathrm{~L}^{+}$cells (median $1.9 \%$ of $\mathrm{CD}^{+} \mathrm{CD} 45 \mathrm{RA}^{+} \mathrm{CD} 62 \mathrm{~L}^{+}$cells in baseline specimens). Changes-from-baseline analysis showed a statistically significant increase in the percentage and absolute number of circulating NCD 4 cells after 6 months of GH treatment. These increases were even more pronounced after 12 months of GH treatment, with a $96.4 \%$ increase in NCD4 cells, compared with a $17.6 \%$ increase in observational controls $(P=0.004$; Figure 4, B and C, left, and Table 2). Smaller GH-associated increases in NCD8 cells were not statistically significant (Figure 4, B and C, right, and Table 2). When CD11a staining was used to more rigorously subdivide

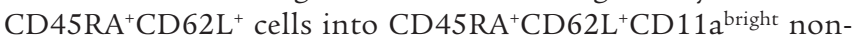
naive $\mathrm{T}$ cells and $\mathrm{CD} 45^{+} \mathrm{CD} 62 \mathrm{~L}^{+} \mathrm{CD} 11 \mathrm{a}^{\mathrm{dim}}$ true naive $\mathrm{T}$ cells, $\mathrm{GH}$ effects on naive $\mathrm{T}$ cell gain were more apparent. This was particularly evident in the $\mathrm{CD} 8{ }^{+} \mathrm{CD} 45 \mathrm{RA}^{+} \mathrm{CD} 62 \mathrm{~L}^{+} \mathrm{CD} 11 \mathrm{a}^{\text {dim }}$ true naive (TNCD8) subpopulation, where GH treatment was associated with a $69.5 \%$ increase in the absolute number of circulating TNCD8 cells (versus $-13.5 \%$ in observational controls; $P=0.023$ ) (Figure 4, $\mathrm{B}$ and $\mathrm{C}$, and Table 2). Comprehensive regression analysis including GH treatment data from observational controls who received $\mathrm{GH}$ in the second year of the study confirmed substantial effects of GH on naive CD4 ${ }^{+} \mathrm{T}$ cells and modest effects on TNCD8 cells (Figure 4, D and E, and Table 3 ).

Total $\mathrm{CD}^{+} \mathrm{T}$ cells also increased with 1 year of $\mathrm{GH}$ treatment (CD4 ${ }^{+} \mathrm{T}$ cell count: $+40.1 \%$ versus $+10.9 \%$ in $\mathrm{GH}$ arm and observational controls, respectively; $P=0.031$ ) (Figure 5 , A and $\mathrm{B}$, and Table 2). Comprehensive regression analysis estimated that gains in the percentage of $\mathrm{CD}^{+} \mathrm{T}$ cells were greater with $\mathrm{GH}$ treatment (15.3\% higher versus no $\mathrm{GH} ; P=0.007)$, as were gains in the total $\mathrm{CD}^{+} \mathrm{T}$ cell count $(14.7 \%$ higher versus no $\mathrm{GH} ; P=0.082)$ (Figure $5 \mathrm{C}$ and Table 3 ). Likewise, $\mathrm{GH}$ treatment was associated with a statistically significant increase in the $\mathrm{CD}^{+} / \mathrm{CD}^{+} \mathrm{T}$ cell ratio (22.0\% higher versus no $\mathrm{GH} ; P=0.002)$. All study participants with a baseline $\mathrm{CD}^{+} \mathrm{T}$ cell count below 200 cells/ $\mu \mathrm{l}\left(n=5\right.$; mean $\mathrm{CD}^{+}$ T cell count, 149; range, 130-172), who received at least 6 months of $\mathrm{GH}$ and had at least 1 year of $\mathrm{CD}^{+} \mathrm{T}$ cell count measurements 


\section{Table 1}

Baseline characteristics

\begin{tabular}{|c|c|}
\hline Measurement ${ }^{A}$ & GH arm, $n=11$ \\
\hline Age (yr) & $50.3(40.0-75.9)$ \\
\hline Duration of stable ARV (yr) & $2.3(1.0-8.5)$ \\
\hline HIV-1 RNA (copies/ml) & $75.0(<75)$ \\
\hline Total CD4+ T cells (cells/ul) & $260.0(112-337)$ \\
\hline Total CD4+ $\mathrm{T}$ cells $(\%)$ & $15.0(6-32)$ \\
\hline Naive CD4+T cells (cells/ul) & $36.0(7-175)$ \\
\hline Naive CD4+ T cells (\%) & $20.4(6.1-52.0)$ \\
\hline Total CD8+ T cells (cells/ul) & $620.0(380-1,638)$ \\
\hline Total CD8+ T cells $(\%)$ & $51.0(32-61)$ \\
\hline Naive CD8+ T cells (cells/ul) & $104.0(44-231)$ \\
\hline Naive CD8+ T cells (\%) & $15.4(7.3-27.4)$ \\
\hline PBMC TRECs (per $10^{5}$ PBMCs) & $737.0(55-6,928)$ \\
\hline NCD4 TRECs (per $10^{5}$ NCD4 cells) & $15,391.0(2,115-109,848)$ \\
\hline NCD8 TRECs (per $10^{5}$ NCD8 cells) & $1,7891.0(128-55,347)$ \\
\hline Thymic density (HU) & $-88.0(-116$ to -52$)$ \\
\hline Thymic index & $1.0(1-2)$ \\
\hline Thymic volume $\left(\mathrm{cc}^{3}\right)$ & $10.8(5.2-25.9)$ \\
\hline CD4+CD38+DR+ cells (cells/ $\mu$ l) & $15.0(8-27)$ \\
\hline CD8+CD38+DR+ cells (cells/ul) & $90.0(40-328)$ \\
\hline IGF-1 (pg/ml) & $151.0(87-663)$ \\
\hline $\mathrm{IL}-7(\mathrm{pg} / \mathrm{ml})$ & $6.4(3.0-18.9)$ \\
\hline Androgen therapy $(n)^{\mathrm{C}}$ & 4 \\
\hline
\end{tabular}

$\begin{array}{cc}\text { Control arm, } \boldsymbol{n = 1 0 ^ { B }} & \boldsymbol{P} \\ 51.0(36.9-65.0) & 0.699 \\ 2.8(1.1-7.7) & 0.342 \\ 75.0(<75-633) & 0.147 \\ 197.0(96-399) & 0.860 \\ 15.0(10-30) & 1.000 \\ 49.0(4-102) & 0.860 \\ 19.4(4.5-41.9) & 0.805 \\ 634.0(392-1,479) & 0.972 \\ 53.0(44-69) & 0.204 \\ 127.0(18-219) & 0.860 \\ 14.5(4.5-35.8) & 0.597 \\ 1,900.0(90-5,763) & 0.680 \\ 7,667.0(2,584-172,963) & 0.761 \\ 3,155.0(760-64,951) & 0.704 \\ -84.0(-106 \text { to }-74) & 0.805 \\ 1.0(0-2) & 0.507 \\ 14.4(9.2-36.7) & 0.218 \\ 13.0(5-30) & 0.418 \\ 77.0(19-459) & 0.341 \\ 184.0(80-319) & 0.732 \\ 6.6(1.3-13.0) & 0.704 \\ 8 & 0.081\end{array}$

AValues are shown as median (range), except for Androgen therapy ( $n$ ). BData excluded from one participant due to onset of systemic illness during the observation year. 'Ongoing androgen therapy at study enrollment (see Study design and participants in Methods for more details); the number of participants receiving androgen therapy at the time of study enrollment is indicated.

after GH initiation, experienced a sustained ( $\geq 2$ independent measurements) increase above the clinically significant threshold of 200 cells/ $\mu \mathrm{l}$ (mean $\mathrm{CD} 4^{+} \mathrm{T}$ cell count at last study visit, 261 ; range, 221-316). In contrast, $\mathrm{GH}$ effects on the percentage or number of circulating total $\mathrm{CD} 8^{+} \mathrm{T}$ cells were minimal (Figure $5, \mathrm{~A}-\mathrm{C}$ ).

Evidence of $\mathrm{T}$ cell activation was examined by flow cytometric analysis of T cells expressing activation markers CD38 and HLA-DR (DR) or Fas. Changes-from-baseline analysis (Supplemental Figure 2; Table 2) suggested an early rise in circulating $\mathrm{CD}_{4}{ }^{+}$and $\mathrm{CD}^{+}{ }^{+} \mathrm{CD} 38^{+} \mathrm{DR}^{+} \mathrm{T}$ cells in the $\mathrm{GH}$ arm that was followed by a decline below baseline by month 12 . Fas ${ }^{+} \mathrm{T}$ cells also appeared to be reduced in the GH arm. Comprehensive regression analysis revealed that $\mathrm{CD} 4^{+} \mathrm{CD} 38^{+} \mathrm{DR}^{+}$and $\mathrm{CD} 8^{+} \mathrm{CD} 38^{+} \mathrm{DR}^{+}$cells were $23.4 \%$ lower $(P=0.036)$ and $32.3 \%$ lower $(P=0.010)$, respectively, with 1 year of $\mathrm{GH}$ and that $\mathrm{CD}^{+} \mathrm{Fas}^{+} \mathrm{T}$ cells were $22.9 \%$ lower with GH $(P=0.006)$ (all compared with no GH) (Table 3 ).

Other than GH effects on $\mathrm{T}$ cells, there were no noteworthy changes in other hematolymphoid lineages with GH treatment, including the number of circulating B lymphocytes, natural killer cells, red blood cells, neutrophils, platelets, or circulating $\mathrm{CD}^{2} 4^{+}$cells (data not shown). Although there were no apparent effects of GH treatment on HIV-1 viral load (Table 3; Supplemental Table 2), our ability to study this parameter was limited by study exclusion of those with high baseline levels of viremia and by the paucity of detectable viremia in most study participants (no detectable viremia was measured in 16 of 21 study participants throughout their study participation, and only low and sporadic bursts of viremia were detected in the remaining study participants). Therefore, no general conclusions can be made regarding the effect of GH on HIV-1 replication and, reciprocally, no conclusions can be made with regard to the impact of HIV-1 viremia on GH effects on the immune system.
Increases in circulating IGF-1 are associated with immunologic changes. As expected, GH treatment was associated with increased circulating levels of IGF-1. Regression analysis showed peak increases in IGF-1 1 month after GH initiation (113.8\% higher versus no GH; $P<0.0001$ ), with sustained increases throughout $\mathrm{GH}$ treatment (Supplemental Figure 3; Table 3). Because IGF-1 mediates many metabolic effects of $\mathrm{GH}$, we investigated whether IGF-1 gains might mediate immunologic changes in GH recipients. Linear regression analysis revealed significant interactions between IGF-1 gain and immunologic changes with GH treatment (Figure 6). GH recipients with an IGF-1 gain equal to or greater than the cohort median ( $\geq 2.2$-fold increase, or "higher IGF-1 gain") had significantly greater increases than those with less than 2.2-fold IGF-1 gain ("lower IGF-1 gain") in the following outcomes: thymic volume, PBMC TREC frequency, percentage and number of circulating $\mathrm{NCD} 4$ cells, percentage of $\mathrm{CD}^{+} \mathrm{T}$ cells, $\mathrm{CD} 4^{+} / \mathrm{CD} 8^{+} \mathrm{T}$ cell ratio; and significantly greater decreases in the percentage and number of circulating $\mathrm{CD} 8^{+} \mathrm{CD} 38^{+} \mathrm{DR}^{+}$cells. GH recipients with higher gains in IGF-1 also experienced greater gains in $\mathrm{CD} 4^{+} \mathrm{T}$ cell count (24.4\% higher versus no GH; $P=0.012$ ) and circulating IL-7 levels (65.1\% higher versus no GH; $P=0.042$ ) (Figure 6; Supplemental Figure 3; Tables 2 and 3). Gains in thymic density appeared similar regardless of GH-associated IGF-1 gain. Of particular interest was the finding that higher gains in IGF-1 appeared to be associated with decreases in naive T cell TRECs. GH recipients with higher IGF-1 gains had a 19.1\% decrease in NCD4 TRECs (compared with a $36.8 \%$ increase in those with lower IGF-1 gains; $P=0.077$ ) and a $35.6 \%$ decrease in NCD8 TRECs (compared with a $58.8 \%$ increase in those with lower IGF-1 gains; $P=0.030$ ). These findings are consistent with the possibility that IGF-1 may promote naive $\mathrm{T}$ cell expansion and dilution of naive $\mathrm{T}$ cell TRECs. 
A
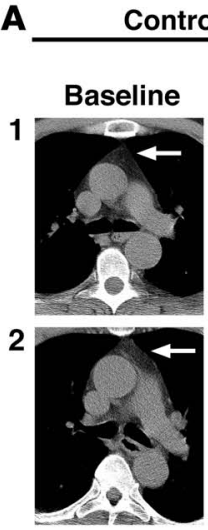

3

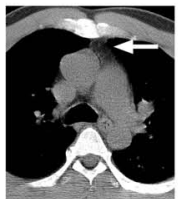

Control Arm
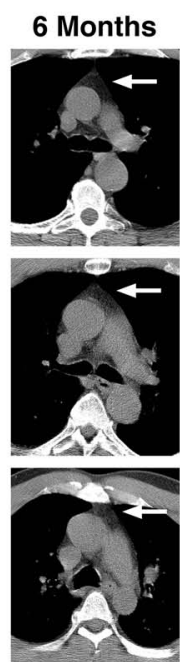

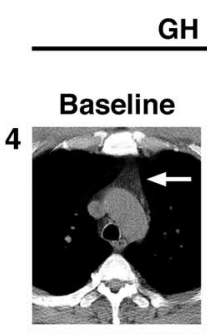

5
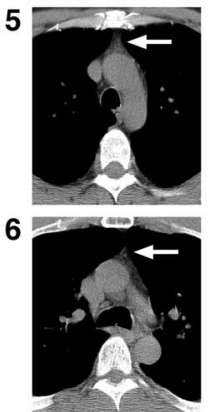

GH Arm
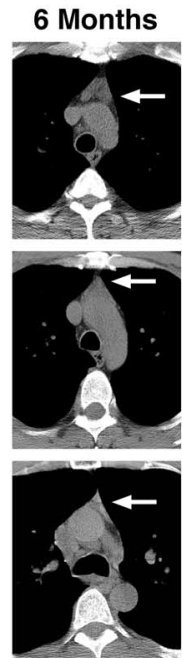

B

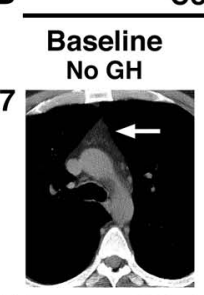

8

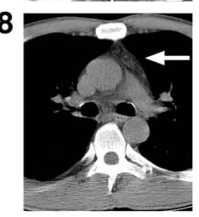

9

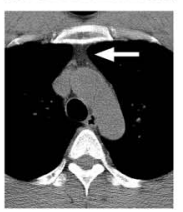

Control Arm Cross-over to GH Treatment
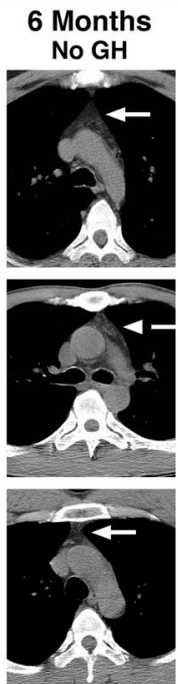
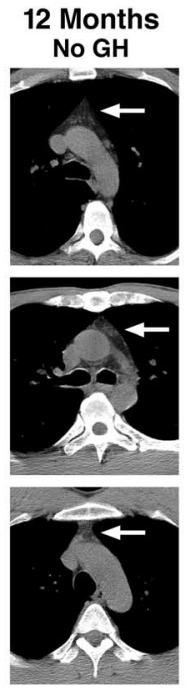

18 Months GH
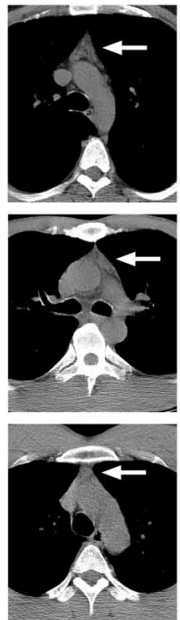

Figure 2

GH treatment is associated with the emergence of dense thymus tissue in HIV-1-infected adults. Representative scans are shown for 9 study participants (numbered 1-9). (A) Cross-sectional comparison of thymus scans from 3 control arm participants (1-3, left panel, no GH) and 3 GH arm participants (4-6, right panel, GH) during the first 6 months of the study. All baseline scans showed low attenuation grayish black adipose tissue in the anterior mediastinum (arrows), consistent with thymic involution. Repeat CT scans obtained 6 months after the baseline scans revealed a marked increase in thymic density in GH recipients (far-right column). This brighter higher-attenuation tissue is consistent with cellular thymus. In contrast, no changes were observed in the absence of GH (second column from left). (B) Longitudinal display of serial thymus CT scans from 3 control arm participants (nos. 7-9) taken at study baseline; 6 months into the study in the absence of GH; pre-GH baseline 12 months into the study; and 18 months into the study after 6 months of GH treatment. As seen in the cross-sectional comparisons, thymus is involuted in the absence of $\mathrm{GH}$, and $\mathrm{GH}$ treatment (far-right column) is associated with the emergence of dense thymus tissue.

Effects after GH discontinuation. Analysis of 8 study participants examined whether the effects of GH disappeared or persisted in the 3 -month period after $\mathrm{GH}$ discontinuation. Comparison of immune measurements taken at the end of GH treatment and 3 months after GH discontinuation revealed additional increases in the percentage $(+21.1 \%, P=0.008)$ and absolute number $(+45.1 \%, P=0.0003)$ of circulating NCD4 cells. In addition, the percentage $(+10.8 \%$, $P=0.020)$ and absolute number $(+17.1 \%, P=0.014)$ of circulating $\mathrm{CD}^{+} \mathrm{T}$ cells increased significantly. NCD8 cells also increased in the 3 -month period after $\mathrm{GH}$ discontinuation $(+23.8 \%, P=0.0003)$. Using regression models, the cumulative effects of 12 months of $\mathrm{GH}$ and 3 months after $\mathrm{GH}$ discontinuation were estimated as a
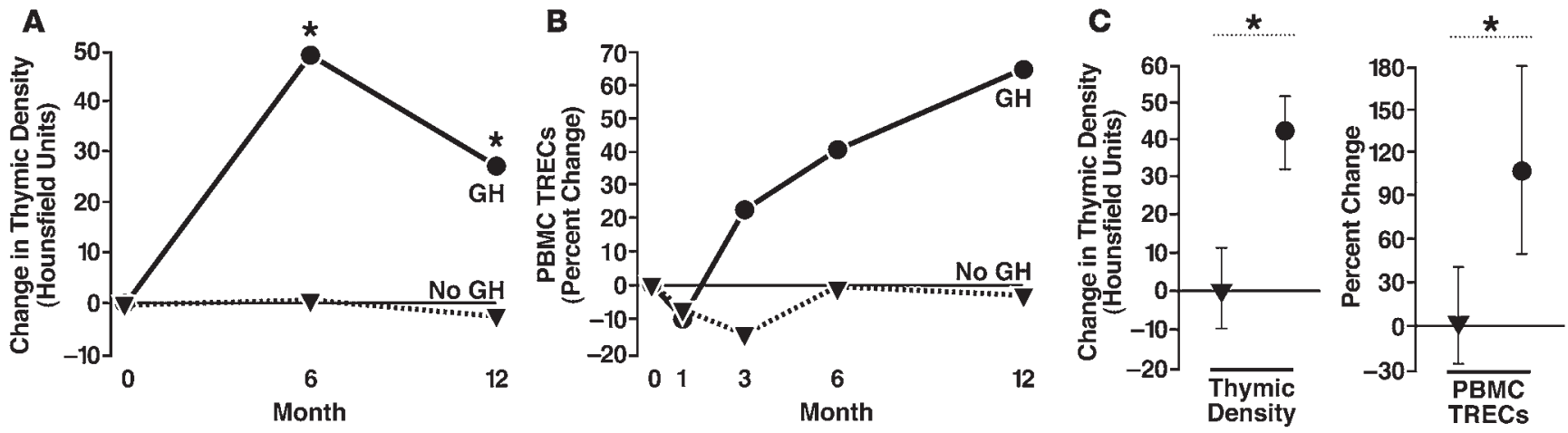

Figure 3

GH treatment is associated with increased thymic density and TREC frequency in HIV-1-infected adults. (A) Comparison of changes in the GH arm versus the control arm over the first year of the study demonstrated significant increases in thymic density in GH recipients at 6 and 12 months after GH initiation. A modest, nonsignificant decrease in thymic density was observed between month 6 and month 12, commensurate with GH dose reduction and consistent with a dose-response effect of $\mathrm{GH}$ on the thymus. No notable changes in thymic density were seen in the absence of GH. (B) The frequency of PBMC TRECs was also increased with GH treatment during the first year of the study. (C) Comprehensive regression analysis, including crossover data of GH treatment of observational controls, demonstrates that GH treatment (circles) is associated with significant increase in thymic density and PBMC TREC frequency compared with no GH. Estimated changes with $95 \%$ Cls are displayed. Regression analysis estimated the effects of 6 months (thymic density) or 1 year (PBMC TRECs) of GH treatment compared with changes in the absence of GH. Median values are displayed in $\mathbf{A}$ and $\mathbf{B}$. Cls and additional data are shown in Tables 2 and 3. ${ }^{*}<0.05$ for comparison of $\mathrm{GH}$ versus no $\mathrm{GH}$. 
Table 2

Changes-from-baseline analysis

\begin{tabular}{|c|c|c|c|c|c|}
\hline Outcome & $\begin{array}{c}n \\
\text { (GH/control) }\end{array}$ & $\begin{array}{c}\text { GH arm }{ }^{\mathrm{A}} \\
\text { (median change }[95 \% \mathrm{CI}] \text { ) }\end{array}$ & $\begin{array}{c}\text { Control arm } \\
\text { (median change }[95 \% \mathrm{CI}] \text { ) }\end{array}$ & Month & $P$ \\
\hline \multirow[t]{2}{*}{ Thymic density } & $11 / 9$ & +50.0 HU (19.0-73.0) & $+1.0 \mathrm{HU}(-7.0-4.0)$ & 6 & 0.0005 \\
\hline & $6 / 8$ & $+27.5 \mathrm{HU}(3.0-81.0)$ & $-2.5 \mathrm{HU}(-3.0-24.0)$ & 12 & 0.044 \\
\hline \multirow[t]{2}{*}{ PBMC TRECS } & $9 / 6$ & +39.8 (8.1-73.2) & $-2.2(-23.1-185.0)$ & 6 & 0.068 \\
\hline & $4 / 5$ & $+62.3(28.8-190.5)$ & $-3.3(-5.7-114.6)$ & 12 & 0.111 \\
\hline \multirow[t]{2}{*}{ NCD4 TRECS } & $11 / 9$ & $+19.8(-20.4-169.1)$ & +8.8 (-28.8-57.8) & 6 & 0.403 \\
\hline & $6 / 8$ & $+43.0(-57.2-133.4)$ & $+13.6(-12.0-274.6)$ & 12 & 0.478 \\
\hline \multirow[t]{2}{*}{ NCD8 TRECS } & $11 / 9$ & $-8.3(-38.1-108.1)$ & $+8.0(-18.8-16.6)$ & 6 & 0.543 \\
\hline & $6 / 8$ & $+44.0(-71.2-915.6)$ & $+30.2(-36.1-859.5)$ & 12 & 0.949 \\
\hline \multirow[t]{2}{*}{$\mathrm{CD} 4+\mathrm{CD} 45 \mathrm{RA}+\mathrm{CD} 62 \mathrm{~L}+(\%)$} & $11 / 10$ & $+20.6(4.5-76.5)$ & $+1.5(-4.0-15.2)$ & 6 & 0.038 \\
\hline & $8 / 8$ & +35.0 (25.5-163.1) & $+2.0(-7.4-29.5)$ & 12 & 0.007 \\
\hline \multirow[t]{2}{*}{ CD4+CD45RA+CD62L+ cells } & $11 / 10$ & +49.6 (27.6-154.9) & $+24.4(-2.3-32.8)$ & 6 & 0.038 \\
\hline & $8 / 8$ & +96.4 (48.6-188.0) & $+17.6(-6.2-57.9)$ & 12 & 0.004 \\
\hline \multirow[t]{2}{*}{ CD4+CD45RA+CD62L+CD11adim (\%) } & $8 / 8$ & $+60.1(7.0-936.1)$ & $-13.7(-24.1-173.0)$ & 6 & 0.024 \\
\hline & $5 / 7$ & +103.2 (33.7-934.4) & $+17.2(-26.4-281.6)$ & 12 & 0.035 \\
\hline \multirow[t]{2}{*}{ CD4+CD45RA+CD62L+CD11a dim cells } & $8 / 8$ & $+89.2(51.4-890.4)$ & $-3.3(-22.7-174.4)$ & 6 & 0.010 \\
\hline & $5 / 7$ & $+259.5(92.4-1,453.0)$ & $+13.9(-27.9-298.9)$ & 12 & 0.023 \\
\hline \multirow[t]{2}{*}{ Total CD4+ T cells (\%) } & $11 / 10$ & $+21.2(-9.1-33.3)$ & $+3.1(-3.7-8.1)$ & 6 & 0.916 \\
\hline & $8 / 8$ & +32.3 (9.1-63.6) & $+7.2(1.6-18.9)$ & 12 & 0.012 \\
\hline \multirow[t]{2}{*}{ Total CD4+ $\mathrm{T}$ cells } & $11 / 10$ & $+11.2(2.7-42.0)$ & $+16.6(-2.6-27.9)$ & 6 & 0.504 \\
\hline & $8 / 8$ & $+40.1(8.5-78.9)$ & $+10.9(-8.9-49.0)$ & 12 & 0.031 \\
\hline \multirow[t]{2}{*}{ CD8+CD45RA+CD62L+ (\%) } & $11 / 10$ & $+8.2(5.4-47.9)$ & $+4.1(-8.9-29.7)$ & 6 & 0.860 \\
\hline & $8 / 8$ & $+21.7(2.9-52.7)$ & $+8.4(-3.1-66.1)$ & 12 & 0.270 \\
\hline \multirow[t]{2}{*}{ CD8+CD45RA+CD62L+ cells } & $11 / 10$ & $+16.6(-12.0-43.8)$ & $+23.7(-0.9-52.8)$ & 6 & 0.699 \\
\hline & $8 / 8$ & $+24.2(-12.2-109.5)$ & $+11.9(-2.8-104.9)$ & 12 & 0.713 \\
\hline \multirow[t]{2}{*}{ CD8+CD45RA+CD62L+CD11adim (\%) } & $8 / 8$ & $+18.4(-9.8-685.7)$ & $-26.4(-48.0$ to -0.1$)$ & 6 & 0.010 \\
\hline & $5 / 8$ & $+78.9(24.4-609.2)$ & $-6.2(-25.8-63.0)$ & 12 & 0.023 \\
\hline \multirow[t]{2}{*}{ CD8+CD45RA+CD62L+CD11 adim cells } & $8 / 8$ & $+32.6(2.6-711.8)$ & $-13.8(-61.6-10.7)$ & 6 & 0.004 \\
\hline & $5 / 8$ & $+69.5(28.0-1,027.6)$ & $-13.5(-33.4-97.2)$ & 12 & 0.023 \\
\hline \multirow[t]{2}{*}{ Total CD8+ T cells (\%) } & $11 / 10$ & $-2.9(-12.6-1.9)$ & $-0.5(-3.4-7.7)$ & 6 & 0.130 \\
\hline & $8 / 8$ & $-2.5(-6.8-5.7)$ & $-2.9(-6.0-9.4)$ & 12 & 0.636 \\
\hline \multirow[t]{2}{*}{ Total CD8+ $T$ cells } & $11 / 10$ & $+0.7(-14.5-30.2)$ & $+6.4(-23.0-38.0)$ & 6 & 0.460 \\
\hline & $8 / 8$ & $-0.1(-25.3-54.9)$ & $+1.5(-14.9-24.3)$ & 12 & 0.875 \\
\hline \multirow[t]{2}{*}{$\mathrm{CD} 4+\mathrm{CD} 38+\mathrm{DR}^{+}(\%)$} & $11 / 10$ & $+12.8(-9.5-66.2)$ & $-12.0(-30.9$ to -8.2$)$ & 3 & 0.045 \\
\hline & $8 / 8$ & $-27.7(-35.7$ to -10.4$)$ & $+0.9(-24.3-215.6)$ & 12 & 0.041 \\
\hline \multirow[t]{2}{*}{$\mathrm{CD}^{+}+\mathrm{FaS}^{+}(\%)$} & $11 / 10$ & $-3.5(-8.0-6.3)$ & $+2.8(-3.1-9.9)$ & 6 & 0.053 \\
\hline & $8 / 8$ & $-8.7(-19.4-5.4)$ & $+3.6(0.2-12.0)$ & 12 & 0.005 \\
\hline \multirow[t]{2}{*}{$\mathrm{CD} 8+\mathrm{CD} 38+\mathrm{DR}^{+}(\%)$} & $11 / 10$ & +26.5 (8.9-75.0) & $-3.4(-15.8-17.4)$ & 3 & 0.015 \\
\hline & $8 / 8$ & $-21.8(-41.6-22.9)$ & $+2.5(-9.9-157.1)$ & 12 & 0.083 \\
\hline \multirow[t]{2}{*}{$\mathrm{CD}^{+} \mathrm{Fas}^{+}(\%)$} & $11 / 10$ & $+0.4(-2.5-11.9)$ & $+11.4(-4.9-17.2)$ & 6 & 0.098 \\
\hline & $8 / 8$ & $-0.5(-18.8-30.8)$ & $+11.7(-3.6-24.8)$ & 12 & 0.156 \\
\hline IGF-1 & $11 / 7$ & $+146.0(104-250.6)$ & $-8.7(-33.3-22.5)$ & 1 & 0.004 \\
\hline IL-7 & $5 / 7$ & $+1.1(-24.6-46.7)$ & $-43.0(-69.6-140.7)$ & 12 & 0.256 \\
\hline
\end{tabular}

Boldface indicates statistically significant $P$ values. ${ }^{A}$ Median change is expressed as percent increase or decrease, with the exception of thymic density.

$127.2 \%$ increase in NCD4 cells and a $32.4 \%$ increase in the $\mathrm{CD}^{+} \mathrm{T}$ cell count. CT analysis of 7 study participants showed an involuted thymus in all 7 at 1 year after GH discontinuation (Supplemental Figure 4). Although the thymus had involuted, changes-frombaseline analysis of T cell gains 1 year after GH discontinuation showed a sustained increase in NCD4 cells $(+119 \%$ compared with pre-GH baseline; $P=0.063)$ and $\mathrm{CD}^{+} \mathrm{T}$ cell count $(+29 \%$ compared with pre-GH baseline; $P=0.063$ ). Because only 7 participants had been followed for a full year after $\mathrm{GH}$ discontinuation at the writing of this article, it is not possible to draw a firm conclusion about extended post-GH immune outcomes at this time.

Baseline predictors of thymic response to GH treatment. Repeatedmeasures regression analysis was performed to determine wheth- er baseline clinical characteristics (e.g., $\mathrm{CD} 4^{+} \mathrm{T}$ cell count, age, or duration of stable ARV) might influence GH effects on the thymus (Supplemental Table 1). Gains in thymic density were significantly greater in those with baseline $\mathrm{CD} 4^{+} \mathrm{T}$ cell counts above the cohort median of 227 cells/ $\mu$ l, and there was a nonsignificant trend toward greater thymic density gains in those at or below the median cohort age of 50. Duration of stable ARV did not appear to influence $\mathrm{GH}$-associated changes in thymus.

Somatotropic hormones such as GH and IGF-1 are thought to enhance thymopoiesis, whereas sex steroids often have a negative effect on thymic function $(24,36)$. We examined whether baseline differences in somatotropic or androgenic hormones might influence thymic response to GH treatment (Supplemental Table 1). 
Table 3

Repeated-measures regression analysis

\begin{tabular}{|c|c|c|c|c|c|}
\hline Outcome & $\begin{array}{c}n, \text { subjects } \\
\text { (measurements) }\end{array}$ & $\begin{array}{l}\text { Change with GH } \\
\text { (vs. no GH) }\end{array}$ & $95 \% \mathrm{Cl}$ & Months of GH & $P$ \\
\hline \multirow[t]{2}{*}{ Thymic density } & $21(61)$ & $+41.9 \mathrm{HU}$ & $31.9-51.8$ & 6 & $<0.0001$ \\
\hline & $21(61)$ & $+38.3 \mathrm{HU}$ & $15.0-61.6$ & 12 & 0.002 \\
\hline Thymic volume & $21(61)$ & $+9.8 \%$ & $-24.8-60.4$ & 12 & 0.619 \\
\hline PBMC TRECs & $20(121)$ & $+101.6 \%$ & $21.4-234.9$ & 12 & 0.007 \\
\hline NCD4 TRECs & $20(88)$ & $-4.8 \%$ & $-12.0-227.4$ & 12 & 0.859 \\
\hline NCD8 TRECs & $20(88)$ & $-27.1 \%$ & $-65.7-54.8$ & 12 & 0.405 \\
\hline CD4+CD45RA+CD62L+ (\%) & $21(163)$ & $+41.4 \%$ & $20.7-65.7$ & 12 & $<0.0001$ \\
\hline CD4+CD45RA+CD62L + cells & $21(162)$ & $+62.1 \%$ & $29.5-102.9$ & 12 & $<0.0001$ \\
\hline CD4+CD45RA+CD62L+CD11adim (\%) & $20(57)$ & $+117.6 \%$ & $24.6-280.0$ & 12 & 0.008 \\
\hline CD4+CD45RA+CD62L+CD11adim cells & $20(57)$ & $+209.0 \%$ & $67.3-470.5$ & 12 & 0.001 \\
\hline Total CD4+ $\mathrm{T}$ cells $(\%)$ & $21(164)$ & $+15.3 \%$ & $4.0-27.9$ & 12 & 0.007 \\
\hline Total CD4+ cells & $21(164)$ & $+14.7 \%$ & $-1.7-33.8$ & 12 & 0.082 \\
\hline CD8+CD45RA+CD62L+ $(\%)$ & $21(163)$ & $+2.6 \%$ & $-12.5-20.4$ & 12 & 0.748 \\
\hline CD8 + CD45RA + CD62L + cells & $21(162)$ & $-4.1 \%$ & $-23.4-20.1$ & 12 & 0.714 \\
\hline CD8+CD45RA+CD62L+CD11adim (\%) & $20(58)$ & $+69.8 \%$ & $-12.0-227.4$ & 12 & 0.111 \\
\hline CD8+CD45RA+CD62L+CD11adim cells & $20(58)$ & $+98.5 \%$ & $-1.7-300.7$ & 12 & 0.056 \\
\hline Total CD8+ $T$ cells $(\%)$ & $21(164)$ & $-4.7 \%$ & $-9.6-0.3$ & 12 & 0.067 \\
\hline Total CD8 ${ }^{+} T$ cells & $21(164)$ & $-6.4 \%$ & $-21.0-10.8$ & 12 & 0.438 \\
\hline $\mathrm{CD}^{+} / \mathrm{CD}^{+}+\mathrm{T}$ cell ratio & $21(164)$ & $+22.0 \%$ & 7.7-38.2 & 12 & 0.002 \\
\hline $\mathrm{CD} 4+\mathrm{CD} 38+\mathrm{DR}^{+}(\%)$ & $21(163)$ & $-34.3 \%$ & -48.1 to -16.8 & 12 & 0.001 \\
\hline CD4+CD38+DR+ cells & $21(162)$ & $-23.4 \%$ & -40.3 to -1.8 & 12 & 0.036 \\
\hline $\mathrm{CD}^{+}+\mathrm{Fas}^{+}(\%)$ & 21 (163) & $-15.5 \%$ & -19.7 to -11.1 & 12 & $<0.0001$ \\
\hline CD4+Fas ${ }^{+}$cells & $21(162)$ & $-2.9 \%$ & $-17.1-13.7$ & 12 & 0.714 \\
\hline CD8+38+DR+ $(\%)$ & $21(163)$ & $-28.1 \%$ & -42.6 to -10.1 & 12 & 0.004 \\
\hline $\mathrm{CD} 8+38+\mathrm{DR}^{+}$cells & 21 (162) & $-32.3 \%$ & -49.5 to -9.1 & 12 & 0.010 \\
\hline $\mathrm{CD}^{+}+\mathrm{Fas}^{+}(\%)$ & $21(163)$ & $-14.6 \%$ & -21.6 to -6.9 & 12 & 0.0004 \\
\hline $\mathrm{CD}^{+} \mathrm{Fas}^{+}$cells & $21(162)$ & $-22.9 \%$ & -35.8 to -7.5 & 12 & 0.006 \\
\hline IGF-1 & 20 (124) & $+113.8 \%$ & $86.5-145.1$ & 1 & $<0.0001$ \\
\hline IL-7 & $20(83)$ & $+46.1 \%$ & $-7.3-130.2$ & 12 & 0.100 \\
\hline HIV-1 RNA & $21(115)$ & $+22.2 \%$ & $-16.6-79.1$ & 12 & 0.300 \\
\hline
\end{tabular}

Boldface indicates statistically significant $P$ values.

GH-associated gains in thymic density were strikingly higher in those with baseline circulating IGF-1 levels above the cohort median of $179.5 \mathrm{pg} / \mathrm{ml}$ and in those with peak baseline $\mathrm{GH}$ secretion levels above the cohort median of $24.2 \mathrm{ng} / \mathrm{ml}$. Thymic volume increase was lower in androgen recipients and greater in those with higher baseline peak GH levels. In regression analysis controlled for androgen receipt, however, there appeared to be little effect of androgen therapy on GH-associated changes in thymic density, the percentage or absolute number of NCD4 or NCD8 cells, the $\mathrm{CD} 4^{+} \mathrm{T}$ cell count, the $\mathrm{CD} 4^{+} \mathrm{T}$ cell percentage, or the frequency of TRECs.

Adverse effects of $\mathrm{GH}$ treatment. Ninety-five percent of $\mathrm{GH}$ recipients experienced adverse events (AEs) of grade 2 or higher. Most $\mathrm{GH}$-associated AEs were well-described effects of GH treatment, including arthralgias, abnormalities in glucose metabolism, edema, and carpal tunnel syndrome. Table 4 shows the most common and noteworthy AEs of this study. We unexpectedly recorded 3 cases of tenosynovitis of the hand. In 2 of these cases, symptoms evolved 6 or more months after GH discontinuation. All cases evolved in the context of at least moderate levels of repetitive hand activity. Three individuals who screened $(n=1)$ or enrolled $(n=2)$ into the study were incidentally diagnosed with lymphoma by radiographic scans performed as a part of the study protocol. Two of these 3 participants did not receive any GH.

\section{Discussion}

Age-associated decreases in thymic function significantly hinder immune reconstitution in immunodeficient adults. We have hypothesized that thymic function can be pharmacologically enhanced in humans and herein present strong support for this hypothesis. In this prospective randomized analysis of HIV-1-infected adults, GH treatment was associated with robust increases in thymic density, frequency of circulating TRECs within PBMCs, and the number of circulating naive $\mathrm{CD}^{+} \mathrm{T}$ cells. Similar changes were not observed in those who did not receive $\mathrm{GH}$. These data offer compelling evidence that $\mathrm{GH}$ enhances human thymopoiesis. Additionally, increased PBMC TREC frequency and $\mathrm{T}$ cell gains were most pronounced in $\mathrm{GH}$ recipients with higher gains in circulating IGF-1 levels. These findings suggest that IGF-1 occupies an important role in GH-mediated enhancement of $\mathrm{T}$ cell production and offer fundamental insight into the mechanism of GH effects on the human immune system.

Further, these findings demonstrate that declines in thymic function are reversible in human adults. Beyond the implications for the development of therapies for HIV-1 disease and bone marrow transplantation, this work also establishes a basis for additional mechanistic and functional studies of thymic recovery.

$\mathrm{GH}$ treatment induced striking radiographic changes in the thymus by 6 months, along with sizeable increases in PBMC TREC frequency and circulating naive $T$ cells, indicating enhanced 
A

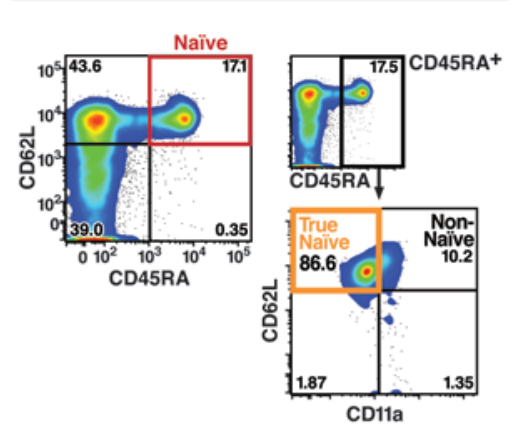

CD8+
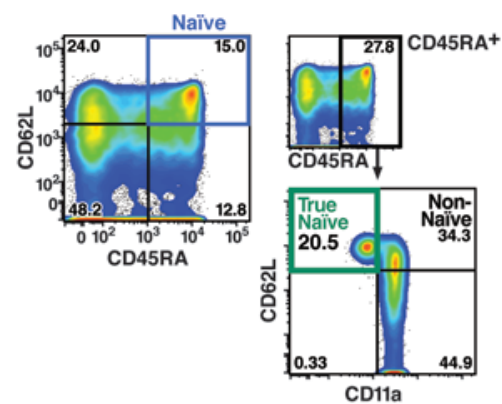

B

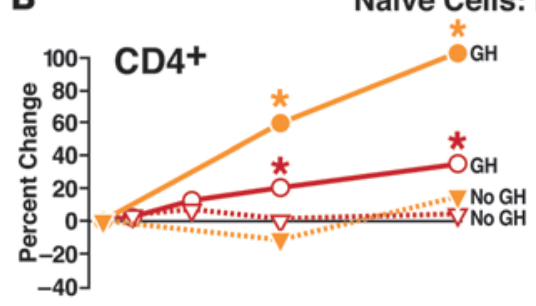

Naïve Cells: Absolute Count
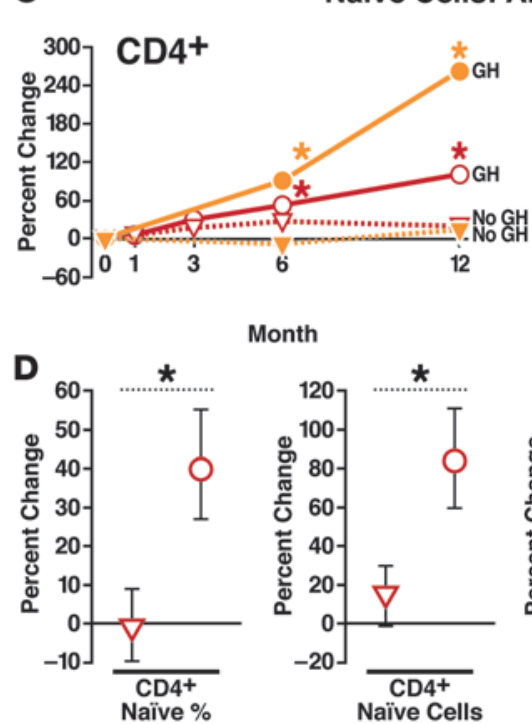

E

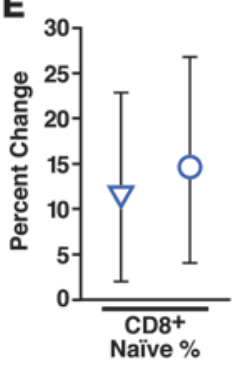

\begin{abstract}
Month
\end{abstract}
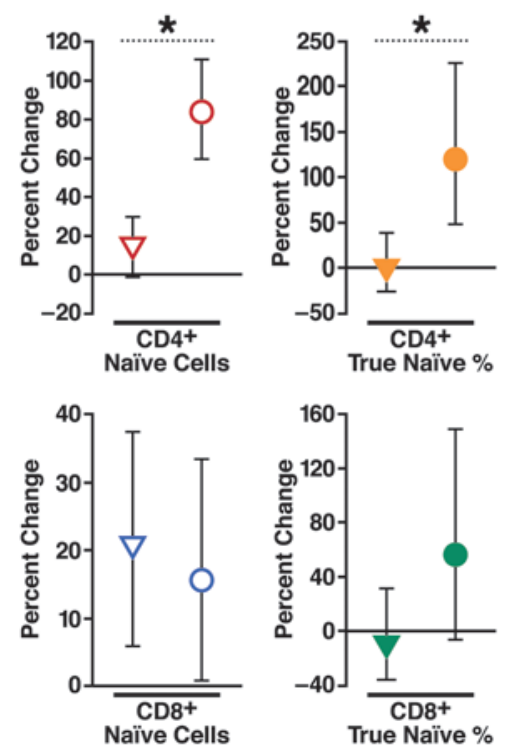
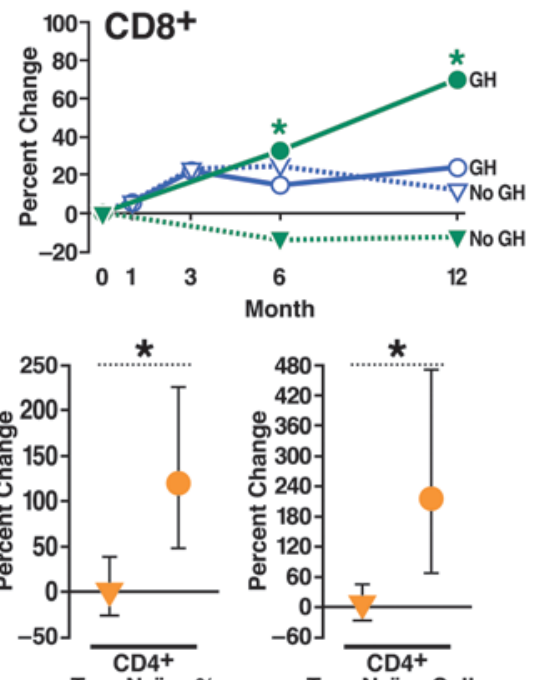

True Naïve Cells

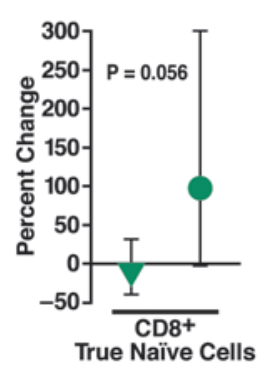

Figure 4

$\mathrm{GH}$ treatment is associated with increases in naive T cells in HIV-1-infected adults. (A) Representative phenotypic analysis of $\mathrm{CD}^{+}$and $\mathrm{CD} 8^{+}$ naive $T$ cells by flow cytometry. CD11a staining was used to identify a subset of non-naive CD45RA ${ }^{+}$CD62 $L+C D 11 a^{\text {bright }} T$ cells and a subset of true naive CD45RA $+C D 62 L+C D 11 a^{\text {dim }} T$ cells. Higher percentages of $C D 45 R A+C D 62 L^{+}$non-naive $T$ cells were observed among CD8 ${ }^{+} \mathrm{T}$ cells. ( $\mathrm{B}$ and C) Comparison of changes in the $\mathrm{GH}$ arm versus observational controls over the first year of the study demonstrated significant increases in the percentage (B, left) and absolute count (C, left) of NCD4 (red) and TNCD4 (orange) cells. There were no increases in the percentage (B, right) and small, nonsignificant increases in the absolute count (C, right) of NCD8 cells (blue) in the GH arm (compared with observational controls) over the first year of the study. TNCD8 (green) increased significantly over the first year of the study in the GH arm. (D) GH-associated increases (circles) in NCD4 cells were confirmed by regression analysis including $\mathrm{GH}$ treatment data from observational controls. (E) $\mathrm{GH}$-associated increases (circles) in TNCD8 cells trended toward statistical significance in comprehensive regression analysis. Estimated changes with $95 \% \mathrm{Cls}$ are shown. Regression analysis estimated the effects of 1 year of GH treatment compared with changes over 1 year in the absence of GH. Median values are shown in $\mathbf{B}$ and $\mathbf{C}$. Cls and additional data are shown in Tables 2 and $3 .{ }^{*} P<0.05$ for comparison of $\mathrm{GH}$ versus no $\mathrm{GH}$. thymic function. Given the close proximity of the thymus to the heart and lungs, histologic confirmation of thymic hyperplasia could not be obtained due to high biopsy risks. Nevertheless, animal studies reporting histologic evidence of thymic hyperplasia with $\mathrm{GH}$ treatment $(26,27)$, in addition to other corroborating data in this study, suggest that the observed radiographic changes represent functional thymus.
Recent thymic emigrants (RTEs) and naive T cells initially traffic to lymphoid tissues. Therefore, GH-associated increases in peripheral lymphocytes may have begun before such changes were detected in peripheral blood, and increases in TREC frequency and naive $\mathrm{T}$ cells may have been underestimated. Nevertheless, the number of circulating $\mathrm{CD} 4{ }^{+} \mathrm{CD} 45 \mathrm{RA}^{+} \mathrm{CD} 62 \mathrm{~L}^{+}$naive $\mathrm{T}$ cells increased markedly with GH treatment. Small increases were also 
A
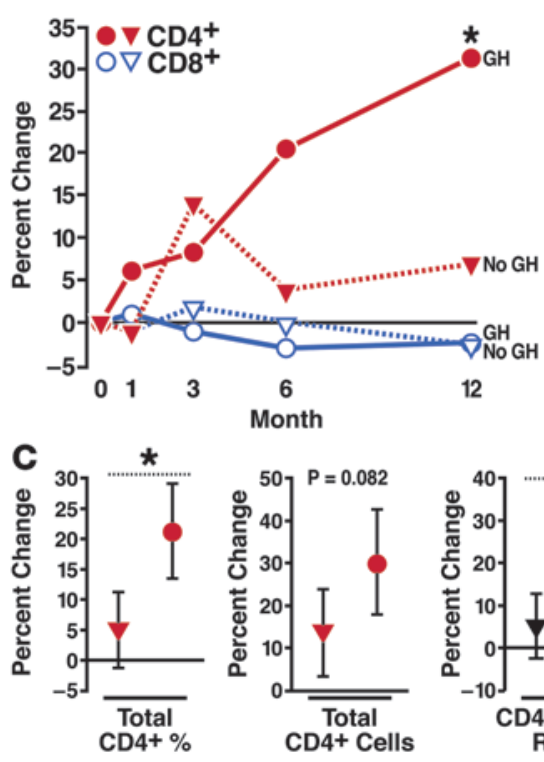

B
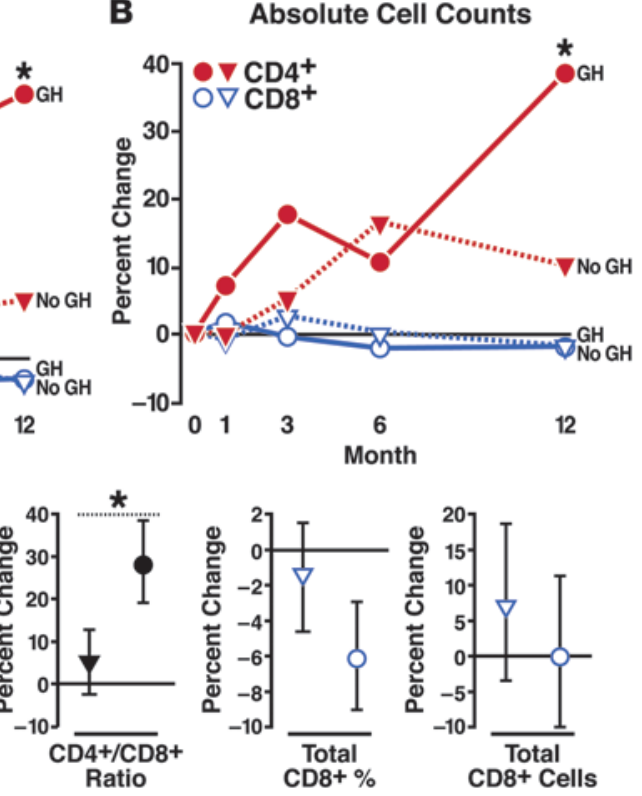
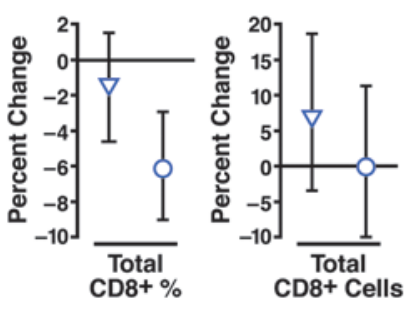

\section{Figure 5}

$\mathrm{GH}$ treatment is associated with increases in total $\mathrm{CD}^{+}{ }^{+} \mathrm{T}$ cells in HIV-1-infected adults. Comparison of changes in the $\mathrm{GH}$ arm versus the observational control arm over the first year of the study showed that $\mathrm{GH}$ treatment was associated with significant increases in the percentage $(\mathbf{A})$ and absolute count (B) of CD4+ ${ }^{+}$cells (red). (C) Comprehensive regression analysis, including crossover data of GH treatment in observational controls, showed that $\mathrm{GH}$ treatment (circles) was associated with significant increases in CD4+ $\mathrm{T}$ cell percentage and the $\mathrm{CD}^{+} / \mathrm{CD}^{+} \mathrm{T}$ cell ratio when compared with no $\mathrm{GH}$. Increases in the absolute count of $\mathrm{CD} 4^{+} \mathrm{T}$ cells trended toward statistical significance in this analysis. There were no remarkable $\mathrm{GH}$-associated changes in the percentage or absolute count of $\mathrm{CD}^{+}{ }^{+} \mathrm{T}$ cells. Estimated changes with $95 \% \mathrm{Cls}$ are shown. Regression analysis estimated the effects of 1 year of GH treatment compared with changes over 1 year in the absence of GH. Median values are shown in $\mathbf{A}$ and $\mathbf{B}$. Cls and additional data are shown in Tables 2 and 3. ${ }^{*} P<0.05$ for comparison of $\mathrm{GH}$ versus no $\mathrm{GH}$. noted in the absence of GH that were comparable to those reported in other HIV-1-infected individuals with good virologic suppression $(6,37)$. Despite enhancing thymopoiesis, GH treatment did not substantially increase the number of $\mathrm{CD} 8{ }^{+} \mathrm{CD} 45 \mathrm{RA}{ }^{+} \mathrm{CD} 62 \mathrm{~L}^{+}$ naive $\mathrm{T}$ cells. However, after non-naive $\mathrm{CD} 8{ }^{+} \mathrm{CD} 45 \mathrm{RA}{ }^{+} \mathrm{CD} 62 \mathrm{~L}^{+} \mathrm{C}$ D11 $\mathrm{a}^{\text {bright }}$ cells were excluded, we did detect considerable gains in naive $\mathrm{CD} 8{ }^{+} \mathrm{CD} 45 \mathrm{RA}^{+} \mathrm{CD} 62 \mathrm{~L}^{+} \mathrm{CD} 11 \mathrm{a}^{\mathrm{dim}}$ cells. CD11a is expressed on $\mathrm{CD}^{+} \mathrm{CD}^{2} 5 \mathrm{RA}^{+} \mathrm{T}$ cells in HIV-1-seronegative and untreated HIV-1-seropositive individuals and is associated with functional characteristics of memory effector cells (33-35). In our ARVtreated subjects, CD11a was expressed on nearly a quarter of $\mathrm{CD}^{+} \mathrm{CD} 45 \mathrm{RA}^{+} \mathrm{CD} 62 \mathrm{~L}^{+}$cells. This finding adds to evidence (38, 39) supporting the use of multiple phenotypic markers to identify naive $\mathrm{CD}^{+} \mathrm{T}$ cells in HIV-1 disease.

GH treatment significantly decreased the percentage and number of $\mathrm{T}$ cells bearing activation markers. Although the mechanisms of this effect are unclear, GH or IGF-1 may diminish immune activation, as STAT5, a major GH signaling molecule, is necessary for regulatory $\mathrm{T}$ cell function $(40,41)$ and IGF-1 has been shown to increase $\mathrm{T}$ cell production of the regulatory cytokine IL-10 (42).

Although GH and IGF-1 enhance multilineage hematopoiesis $(26,43-46)$, GH treatment did not appear to be associated with substantial changes in circulating hematopoietic cells. The number of circulating CD34+ cells (a population that presumably includes prethymic progenitor cells) was not altered. This finding suggests that $\mathrm{GH}$ does not enhance thymopoiesis by enhancing bone marrow export of prethymic progenitor cells. We cannot, however, rule out potential effects of GH or IGF-1 on the ability of progenitor cells to successfully engraft and develop in the thymic microenvironment (47).

IGF-1, a proximal mediator of the metabolic action of $\mathrm{GH}$, had a key role in the immunologic effects of GH treatment. After 1 year, subjects with higher gains in circulating IGF-1 had 93\% more naive $\mathrm{CD}^{+} \mathrm{T}$ cells, $24 \%$ more total $\mathrm{CD} 4^{+} \mathrm{T}$ cells, and a $235 \%$ increase in PBMC TREC frequency compared with subjects not receiving GH. However, GH treatment increased thymic density regardless of IGF-1 gains. This may indicate that $\mathrm{GH}$ exerts direct effects on the thymus or that its thymic effects are mediated by IGF-1 in a primarily paracrine manner (48). Nevertheless, baseline levels of IGF-1 and GH secretion were strong and independent predictors of the thymic response to $\mathrm{GH}$, and it is possible that higher basal somatotropic tone may preserve the ability of the thymus to recover function.

While GH-associated gains in thymic density, PBMC TREC frequency, and naive $T$ cells point strongly to enhancement of thymopoiesis, there are alternative interpretations of these data. For instance, since an increased frequency of naive $T$ cell TRECs has been reported in association with increased thymic function in humans $(22,23)$, it is not clear why an increase in naive $T$ cell TREC frequency was not observed in our $\mathrm{GH}$ recipients. This observation raises the possibility that gains in T cells and PBMC TREC frequency may be due to other GH effects, such as decreased $\mathrm{T}$ cell activation. Although analysis of mechanisms was not a primary goal of the study, we explored this possibility further by using repeated-measures regression models to estimate how much of the effect of GH on major outcomes of interest (NCD4 count, total $\mathrm{CD}^{+} \mathrm{T}$ cell count, and PBMC TREC frequency) might be mediated by changes in 3 key variables: thymic density, circulating IGF-1, and $T$ cell activation (data not shown). The results, combined, suggest an important role for IGF-1 on both central and peripheral compartments, a complementary role of thymic density, and no evident role of T cell activation. More specifically, the models estimate that GH-associated increases in NCD4 cells would be $52 \%$ lower in the absence of GH-associated increases in circulating IGF-1 and $71 \%$ lower in the absence of GH-associated changes in IGF-1 and thymic density. A similar role for IGF-1 and thymic density was found for $\mathrm{GH}$-associated gains in total $\mathrm{CD} 4^{+} \mathrm{T}$ cells. Gains in PBMC TREC frequency also appeared to be highly dependent on IGF-1, suggesting that IGF-1 is a major indicator (and probable mediator) of most GH effects on the immune system. Additional statistical models suggest that altered $T$ cell activation does not appear to influence GH-associated gains in T cells or PBMC TREC frequency. Another possible explanation for the unexpectedly low frequency of naive T cell TRECs is that GH treatment led to altered trafficking of RTEs. Thus, murine studies have demonstrated that 

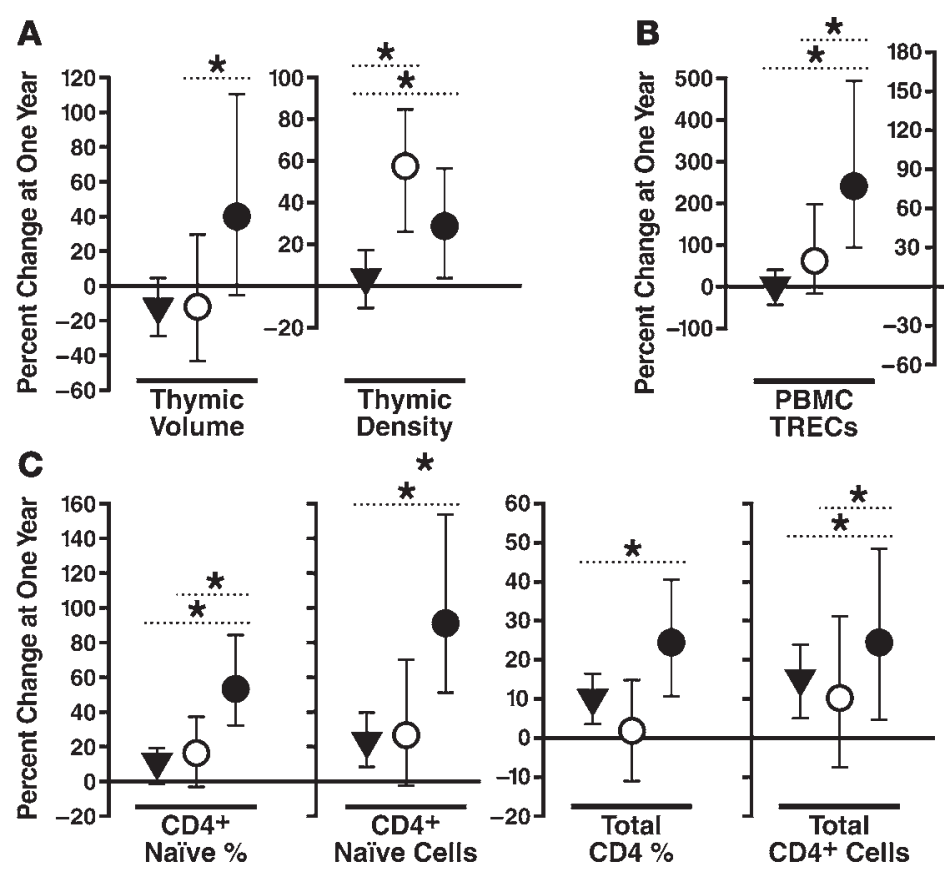
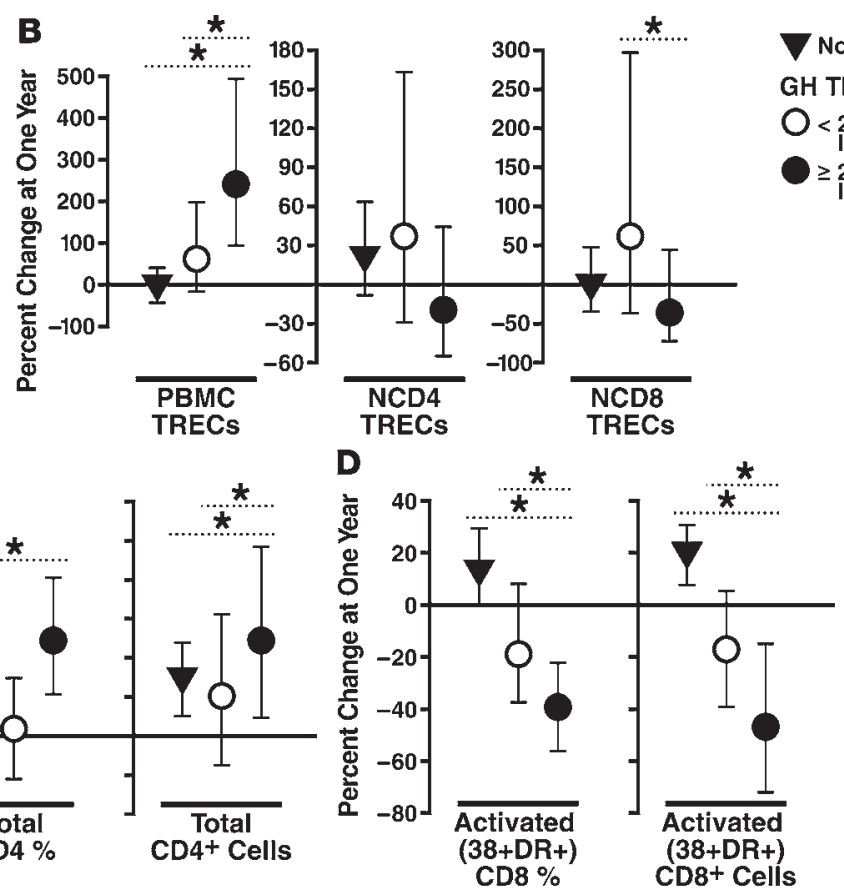

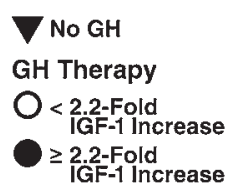

\section{Figure 6}

Increases in circulating IGF-1 are associated with immunologic changes in GH-treated HIV-1-infected adults. Regression analysis data revealed that changes in naive and total $C D 4^{+} T$ cells $(\mathbf{C})$, activated CD8 ${ }^{+} C D 38^{+} D R^{+}$cells (D), and circulating IL-7 levels (E) are associated with GH-induced increases in IGF-1. (B) Higher levels of IGF-1 appear to increase the frequency of PBMC TRECs but decrease the frequency of naive T cell TRECs. (A) GH treatment increased thymic density regardless of IGF-1 gain; however, higher gains in IGF-1 were associated with increased thymic volume. These results suggest that IGF-1 mediates several GH effects on the human immune system. Estimated changes with $95 \% \mathrm{Cls}$ are shown. Analysis estimated the effects of 1 year of $\mathrm{GH} .{ }^{*} P<0.05$ for indicated comparisons.

GH therapy promotes the accumulation of RTEs in peripheral lymphoid tissues by increasing RTE expression of adhesion molecules $(49,50)$. IL-7 and thyroid hormone also have been found to promote accumulation of TREC-bearing naive T cells and RTEs in lymphoid tissues $(51,52)$.

Finally, the discrepancy between PBMC and naive TREC findings raises yet another important mechanistic question: are GHassociated $\mathrm{T}$ cell gains attributable to increased thymic function, peripheral expansion, or both? In this respect, we postulate that $\mathrm{GH}$ treatment enhances both thymopoiesis and peripheral naive $\mathrm{T}$ cell expansion, possibly through the effects of IGF-1. Evidence for central (thymopoietic) effects of GH and IGF-1 in this study include: (a) prominent increases in thymic density, PBMC TREC frequency, and naive T cells with GH treatment; (b) gains in thymic density in the GH arm that were positively correlated with gains in the percentage and absolute count of NCD4 cells (Spearman rank correlation coefficients were $\geq 0.70$ and reached $[P<0.05]$ or trended toward $[P<0.12]$ statistical significance [data not shown]); and (c) a $235 \%$ increase in PBMC TREC frequency $(P=0.0001)$ in those GH recipients with higher gains in IGF-1. Similarly, repeated-measures analysis (described above) estimates that the level of circulating IGF-1 measured 1 month after GH initiation appears to explain $80 \%-100 \%$ of PBMC TREC frequency increases. Data from this study also suggest that GH treatment increases naive $\mathrm{T}$ cell expansion in the periphery. Thus, higher GH-associated gains in IGF-1 were associated with an increased frequency of PBMC TRECs but a decreased frequency of naive T cell TRECs. Higher gains in IGF-1 were also associated with a markedly higher increase in NCD4 cells. These findings suggest that IGF-1 may enhance naive $\mathrm{T}$ cell expansion, a hypothesis that is supported by ex vivo data from our laboratory demonstrating that human naive $T$ cells express high levels of IGF-1 receptor and that IGF-1 treatment directly enhances human naive $T$ cell proliferation (L.A. Napolitano, unpublished observations).

Given the above consideration, we propose that GH-associated increases in thymic density, PBMC TREC frequency, and NCD4 cells represent de novo $\mathrm{T}$ cell production, with possible increases in peripheral $\mathrm{T}$ cell expansion. $\mathrm{GH}$ treatment was associated with a $30 \%$ increase in the $\mathrm{CD}^{+} \mathrm{T}$ cell count, whereas the 1-year increase in the absence of $\mathrm{GH}$ was $13 \%$, representing a 2.4 -fold increase in $\mathrm{CD}^{+} \mathrm{T}$ cell recovery over 1 year (absolute increases of 73 versus 30 cells/ $\mu$ l per year, respectively). Of note, $\mathrm{CD}^{+} \mathrm{T}$ cell gains continued at least 3 months beyond GH discontinuation, and analysis of 7 patients suggested that, despite reinvolution of the thymus, $\mathrm{T}$ cell gains persisted for at least 1 year after $\mathrm{GH}$ discontinuation. Five $\mathrm{GH}$ recipients with a baseline $\mathrm{CD}^{+} \mathrm{T}$ cell count of less than 200 cells/ $\mu \mathrm{l}$ experienced a sustained increase above the clinically significant threshold of 200 cells $/ \mu 1$, with mean CD $4^{+} \mathrm{T}$ cell counts increasing from a baseline of 149 to 261 cells/ $\mu$ lat the final study visit. While these findings hold great promise, additional research is necessary to determine whether thymic recovery is associated with correlates of immune protection. It is feasible that enhanced thymopoiesis may generate increased breadth of the TCR repertoire. Such changes could improve immunity against pathogens, including HIV-1. It is also important to determine whether a recovered thymus retains the ability to successfully execute positive and 


\title{
Table 4
}

\author{
Adverse events
}

Adverse events ${ }^{A, B}$

General body: arthralgia, myalgia, tenosynovitis, diaphoresis, fatigue, insomnia

Edema

Carpal tunnel syndrome, paresthesia

Hyperglycemia: fasting

Hyperglycemia: nonfasting

Hyperamylasemia/hyperlipasemia

Fasting hypertriglyceridemia

Transaminitis (elevations in aspartate and alanine aminotransferase recorded separately)

Malignancy

\begin{tabular}{cccc}
\multicolumn{2}{c}{ GH recipients $^{\mathbf{C}}$} & \multicolumn{2}{c}{ Untreated or off treatment } \\
Grade 2 & Grade 3-4 & Grade 2 & Grade 3-4 \\
$27(13)$ & 1 & $3(2)$ & $3(3)$ \\
$3(3)$ & 0 & 0 & 0 \\
$7(5)$ & 1 & 0 & 0 \\
$3(2)$ & 0 & 0 & 0 \\
$5(3)$ & 0 & $2(2)$ & 0 \\
$3(3)$ & 1 & 0 & 0 \\
0 & $4(2)$ & $5(4)$ & 0 \\
$11(4)$ & $2(1)$ & $5(3)$ & 0 \\
0 & 1 & 0 & 1
\end{tabular}

AThe most common and noteworthy AEs of this study are shown. Ninety percent of GH recipients experienced at least one grade 2 or higher AE that was considered to be definitely or probably related to GH. Eighty-nine percent of those who were untreated or off GH reported at least one grade 2 or higher $\mathrm{AE}$, and none were considered to be definitely or probably related to $\mathrm{GH}$. BIn total, 123 grade $2(86 \%)$ or higher (14\%) AEs were recorded during the study, and $63 \%$ occurred in $\mathrm{GH}$ recipients. Forty-nine percent of $\mathrm{AEs}$ in $\mathrm{GH}$ recipients were considered to be definitely or probably related to $\mathrm{GH}$, and $38 \%$ possibly related to $\mathrm{GH}$. The total number of events for each $\mathrm{AE}$ is shown, with the number of participants experiencing each $\mathrm{AE}$ in parentheses. ${ }^{\mathrm{C}} \mathrm{Receipt}$ of $\mathrm{GH}$ within the previous 3 months. DIncludes pretreatment baseline values for all enrollees; longitudinal data from untreated controls; and data from those who had not received GH for more than 3 months.

negative selection so that newly made $\mathrm{T}$ cells provide effective immune protection without increased autoreactivity. Additional studies are warranted to further explore the effects of GH on the quality of immune function and to explore specific mechanisms of $\mathrm{GH}$ effects on the central and peripheral immune compartments.

The encouraging results of this study invite further consideration of how enhancement of thymopoiesis might be applied to the care of patients with HIV-1 infection. Individuals with advanced lymphopenia despite effective ARV and extended virologic suppression (such as the participants in this study) are likely to have thymic involution (2) and would be most likely to benefit from enhanced thymopoiesis. It is also possible that therapies designed to enhance thymopoiesis may offer benefit if coadministered at initiation of effective ARV. Nevertheless, we do not believe that the findings of this study support the general use of GH treatment in the setting of HIV-1 disease at this time, as it is not possible to determine whether these GH-associated changes in immunologic correlates confer true clinical benefit. Also, the predominance of white males in our study, and the selection of individuals most likely to benefit from increased thymopoiesis, may limit the generalizability of our findings. Finally, this study included only ARV-treated patients with well-suppressed HIV-1 viremia. The use of GH in the setting of uncontrolled HIV-1 replication has not been studied, and therefore, its use should be avoided in the absence of virologic control.

GH has been safely administered to HIV-1-infected patients for wasting and in research studies of HIV-1 lipodystrophy (30, 53-56). Most AEs in this study were mild and resolved with time or adjustment of GH dosing. Nonetheless, the potential benefit of $\mathrm{GH}$ must be weighed against the potential toxicity of treatment. Although we excluded enrollment of those at greatest risk for $\mathrm{GH}$ toxicity, we documented several adverse effects of GH treatment. Dose adjustment or discontinuation was required for diabetes or hyperglycemia in $22 \%$ of GH recipients, despite normal baseline glucose tolerance. All glucose abnormalities resolved with GH discontinuation. Of greater concern were 3 cases of lymphoma -2 in patients who did not receive $\mathrm{GH}$ - detected incidentally by radiographic studies during screening or study visits. Since lymphoma is relatively common in the setting of advanced immunodeficien- cy, subjects at highest risk for lymphoma would likely be included in any study of immune reconstitution. This possibility should be considered in the design of future studies with GH, or other potential immune-based therapies such as IL-7, and emphasizes the need to identify the specific mechanisms that mediate thymic recovery so that more narrowly targeted therapies can be developed.

In summary, we have shown that GH treatment is associated with enhanced thymopoiesis and peripheral T cell recovery. Many immune effects appear to be mediated by IGF-1, and it is possible that GH or IGF-1 also enhances $\mathrm{T}$ cell gains by promoting expansion of peripheral $\mathrm{T}$ cells. To our knowledge, this is the first intervention to successfully increase thymic function in humans. These promising findings have significant applications for the development of immune-based therapies in HIV-1 disease and other immunodeficient states and present substantial opportunity to explore mechanisms that mediate thymic recovery.

\section{Methods}

\section{Study design and participants}

Twenty-two participants were enrolled into a single-center, 2-year prospective, randomized, open-label, crossover study that was approved by the Committee on Human Research of UCSF. One-half of the participants were randomized to receive $\mathrm{GH}$ in the first year ( $\mathrm{GH}$ arm), and one-half were randomized to receive GH in the second year (control arm) (Figure 1). All study visits took place at the San Francisco General Hospital (SFGH) Clinical Research Center (CRC), where participants completed a symptom questionnaire and underwent a history and physical exam, phlebotomy, radiographic studies, oral glucose tolerance testing, and GH secretion testing at various time points. All study analyses were performed at identical intervals for the GH arm and observational control arm during the first year of the study. In the first year, thymus CT scans were performed at baseline, month 6, and month 12. Immune analyses and IGF-1 assays were performed every 1-3 months, except for the analysis of true naive T cells, which was performed every 6 months throughout the study. Observational control participants were tested at identical intervals in years 1 and 2 of the study, so changes that occurred with crossover to GH treatment could be compared. Post-GH visits of GH arm participants were performed every 
3-6 months: immune analyses were performed 3, 6, and 12 months after GH discontinuation, and thymus CT scan was repeated 1 year after GH discontinuation. All visits occurred in the morning, and participants fasted for at least 8 hours before each visit.

Major inclusion criteria included: age of at least 18; serologic or viral load documentation of HIV-1 infection; effective ARV without intensification for at least 1 year; documentation of $\mathrm{CD} 4^{+} \mathrm{T}$ cell count of less than $400 \mathrm{cells} / \mu \mathrm{l}$ at least once within the past 6 months and at screening visit; and documentation of viral load of less than 1,000 copies $/ \mathrm{ml}$ for at least 1 year and at screening visit. Major exclusion criteria included: abundant thymus by CT scan (thymic index >2; ref. 15); abnormal glucose metabolism as defined by fasting blood glucose of greater than $110 \mathrm{mg} / \mathrm{dl}$ or 2-hour oral glucose tolerance test with 2-hour glucose of greater than $140 \mathrm{mg} / \mathrm{dl}$, or diabetes; preexisting neoplasm excepting limited cutaneous Kaposi sarcoma or skin malignancy; preexisting carpal tunnel syndrome without surgical release; preexisting pancreatitis; active cardiac disease; circulating levels of liver or pancreatic enzymes 3 -fold greater than the upper limit of normal; prior administration of immunomodulatory treatment or high-dose chemotherapy; pregnancy or breast-feeding; and severe illness or active AIDS-defining opportunistic infection within 1 month of enrollment.

Thirty-three consenting candidates were screened, and 22 participants were enrolled. Although the study was open to women, all participants were male. Seventeen participants were non-Hispanic and white, and 1 participant was non-Hispanic and more than 1 race. Two participants were Hispanic and more than one race, 1 was Hispanic and white, and 1 was Hispanic with unknown race. At study entry, 2 participants provided confirmation of chronic HCV infection, 17 provided confirmation of $(n=4)$ or self-reported $(n=13)$ negative HCV testing, and 3 had unknown HCV status. Twelve participants were receiving ongoing stable androgen therapy (physiologic replacement) at the time of study enrollment. The median duration of therapy was 2 years in the GH arm and 4 years in the control arm $(P=0.27)$. Indications for androgen therapy were hypogonadism $(n=7)$, hypogonadism with AIDS wasting syndrome $(n=4)$, or AIDS wasting syndrome with probable hypogonadism $(n=1)$. Participants were required to continue on effective ARV throughout the study. Changes in ARV regimen were permitted during the study if performed by the participant's primary care provider. ARV discontinuation resulted in termination from the study.

Nine participants were terminated from the study prior to 24 months: 5 from the GH arm and 4 from the observational control arm. Five early terminations occurred as a result of premature GH discontinuation. Four additional early study terminations were due to illness $(n=2)$, cessation of $\operatorname{ARV}(n=1)$, or elective study withdrawal $(n=1)$.

\section{GH treatment}

Participants were treated with recombinant human GH (Serono Inc). Per protocol, the initial GH dose was $3 \mathrm{mg} / \mathrm{d}(30-40 \mu \mathrm{g} / \mathrm{kg} / \mathrm{d})$ administered by subcutaneous injection on an outpatient basis, followed by dose reduction to $1.5 \mathrm{mg} / \mathrm{d}$ for the final 6 months of the treatment period. GH was administered between 7 and 10 p.m. Premature GH dose reduction was prescribed as indicated by AEs. Early discontinuation of GH was prescribed by the study investigators in 3 instances: 2 due to diabetes and 1 due to carpal tunnel syndrome. Premature GH discontinuation, not indicated from a toxicity standpoint, was performed by 2 study participants without consulting the study team. In 7 additional participants, GH dosing was held temporarily or prematurely reduced by at least $50 \%$ to manage AEs. The median duration of GH treatment was 96\% (11.5 months) of the planned 1-year treatment, and the median cumulative GH dose was $91 \%$ of the planned cumulative study dose in GH arm participants.

\section{Thymus analysis}

Noncontrast helical CT images of the thymus were obtained with $120 \mathrm{kVp}$ and $90 \mathrm{~mA}$ on a single-slice helical CT scanner (CT/i; GE Medical Systems). Contiguous $5-\mathrm{mm}$ images were acquired from the sternal notch to the base of the heart and analyzed by a thoracic radiologist on an offline workstation (Advantage Windows; GE Medical Systems) blinded to the treatment status of the participants being analyzed. Thymic index (TI) was assigned by the radiologist as previously reported (15), and computer-based density and volume analysis of thymus was performed by the radiologist as described previously (31) (Supplementary Figure 1). Density estimation was reported in $\mathrm{HU}$, referenced with respect to water (structures with density greater than water have $\mathrm{HU}>0$, and those less dense than water have $\mathrm{HU}<0$ ). Agreement between the TI and computerbased density measurement was strong $(r=0.81, P<0.0001)$, and changes in TI closely paralleled HU changes.

\section{Laboratory measurements}

Flow cytometry. Analysis of circulating mononuclear cells was conducted on freshly acquired whole-blood specimens using multiparameter flow cytometry. This work was performed in the UCSF Core Immunology Laboratory by individuals blinded to treatment status. Whole blood $(100 \mu \mathrm{l})$ was incubated with fluorochrome-conjugated antibodies directed against phenotypic surface antigens. The following antibody panels were used: CD45-FITC/CD16+CD56-PE/CD19-ECD/CD3-PC5; CD45RA-FITC/ CD62L-PE/CD4 or CD8-ECD/CD3-PC5; DR-FITC/CD38-PE/CD4 or CD8-ECD/CD3-PC5; CD27-FITC/CD28-PE/CD4 or CD8-ECD/CD3PC5; CD8-FITC/CD95-PE/CD4-ECD/CD3-PC5; and CD7-FITC/CD34PE/CD45-PC5; antibodies directed against DR, CD38, CD27, CD28, CD95, CD7, and CD34 were from BD Biosciences, and the remaining antibodies were from Beckman Coulter. For analysis of true naive $\mathrm{CD} 4^{+}$ or $\mathrm{CD}^{+} \mathrm{T}$ cells, CD11a-FITC (BD Biosciences - Pharmingen)/CD45RAECD (Beckman-Coulter)/CD62L-APC (eBioscience)/CD4-PE-Cy7 (BD Biosciences)/CD8-APC-Cy7 (eBioscience)/CD3-Pacific Blue (BD Biosciences - Pharmingen) were used. Red blood cells were lysed after antibody incubation. Data acquisition and analyses were performed using a Coulter Epics XL flow cytometer with System II software, version 3.0 (Beckman Coulter), with the exception of the true naive panel, which was acquired on a BD Digital Vantage or LSRII flow cytometer and analyzed by Flow Jo (Tree Star Inc) software. CD34+ cells were gated as $\mathrm{CD} 45^{+}$, side-scatter low, and $\mathrm{CD} 34^{+}$. Due to the low number of CD34-positive cells, a control sample of CD34-positive cells (CD-Chex CD34; Streck Laboratories) was included for quality control with each measurement.

Clinical laboratories. Routine laboratory tests, including complete blood count with differential; $\mathrm{CD}^{+}$and $\mathrm{CD} 8^{+} \mathrm{T}$ cell percentage and cell count; HIV-1 viral load analysis (Bayer; Versant HIV-1 RNA 3.0 bDNA assay); HIV-1 serology; and complete chemistry panel including pancreatic enzymes, fasting lipids, and glucose measurements were performed by the SFGH Clinical Laboratory. Two-hour oral glucose tolerance test was performed with glucose measurements drawn at baseline and 2 hours after oral ingestion of a 75 -g dextrose load.

\section{Hormone analysis}

IGF-1 assay. IGF-1 levels were measured in duplicate from serum (stored at $-20^{\circ} \mathrm{C}$ until analysis) by the SFGH CRC Core Hormone Laboratory using an immunoradiometric assay (Nichols Institute Diagnostics).

GH assay. GH secretion was measured on the day of study enrollment using standardized stimulation testing. An intravenous bolus of $1 \mu \mathrm{g} / \mathrm{kg}$ GH-releasing hormone (GHRH) (Geref Diagnostic; sermorelin acetate for injection, Serono Inc.) was given, followed immediately by intravenous administration of $0.5 \mathrm{~g} / \mathrm{kg}$ arginine hydrochloride (maximum dose $30 \mathrm{~g}$ ) 
administered over 30 minutes. Blood was collected -15, 0, 15, 30, 45, 60, 90 , and 120 minutes relative to GHRH administration. Serum was frozen at $-20^{\circ} \mathrm{C}$ until analysis. Specimens from all time points were analyzed in duplicate by the SFGH CRC Core Hormone Laboratory, using the Human Growth Hormone Enzyme Immunoassay Kit (American Laboratory Products Co.). The level of peak GH secretion was identified as the specimen with the highest $\mathrm{GH}$ value. $\mathrm{GH}$ deficiency was defined as peak $\mathrm{GH}$ secretion less than $7.5 \mathrm{ng} / \mathrm{ml}$ at study entry $(n=3)(57)$. GH peak ranged from 10.4 to $50.6 \mathrm{ng} / \mathrm{ml}$ in the remaining participants.

\section{TREC analysis}

PBMCs were purified by standard Ficoll gradient centrifugation. After cell washing and aspiration of all supernatant, cells were stored as a dry pellet of 1 million cells at $-80^{\circ} \mathrm{C}$ until analysis. NCD4 or NCD8 cells were purified from freshly ficolled PBMCs by cell sorting on a standard or digital BD FACSVantage flow cytometer and stored at $-80^{\circ} \mathrm{C}$ until analysis. Just prior to performing PCR, DNA was isolated from the cell pellet using a QIAamp DNA Blood Mini Kit (QIAGEN) according to the manufacturer's instructions. Purified DNA was quantified and satisfactory quality confirmed by the optical density 260:280 ratio.

Delta-deletion "signal joint" TRECs formed by $\delta$ Rec- $\psi J \alpha$ rearrangement were amplified using a highly sensitive nested PCR assay (adapted from refs. 22, 58). First-round PCR was performed in a $100-\mu l$ reaction containing $150 \mathrm{ng}$ of purified DNA in magnesium-containing PCR buffer with dNTPs and Ex Taq DNA Polymerase (all from Takara) and outer TREC primers 5'-CAGCCCTCTCCAAGGCAAAAT-3' (forward) and 5'-ACATTTGCTCCGTGGTCTGTG-3' (reverse). The reaction used a 10-minute melting step at $94^{\circ} \mathrm{C}$, followed by 30 seconds at $94^{\circ} \mathrm{C}, 30$ seconds at $60^{\circ} \mathrm{C}$, and 2 minutes at $72^{\circ} \mathrm{C}$ for 25 cycles. One-tenth $(10 \mu \mathrm{l})$ of first-round product was removed in duplicate into a second-round real-time amplification in a 30- $\mu 1$ reaction containing Taqman Universal PCR Mix (Applied Biosystems) with dNTPs, Ex Taq DNA Polymerase, and internal TREC primers 5'-CCCTTTCAACCATGCTGACAC-3' (forward) and 5'-GGGTGCAGGTGCCTATGC- $3^{\prime}$ (reverse). The reaction was performed at $50^{\circ} \mathrm{C}$ for $2 \mathrm{~min}$ utes, $95^{\circ} \mathrm{C}$ for 2 minutes and 40 cycles of $95^{\circ} \mathrm{C}$ for 15 seconds followed by $58^{\circ} \mathrm{C}$ for 1 minute. TRECs were quantified by real-time PCR using a fluorescently labeled oligonucleotide as a reporter probe: $5^{\prime}$-TCTGGTTTTTGTAAAGGTGCCCACTCCTG-3'. An ABI PRISM 7700 (Applied Biosystems) was used for amplification and detection, and $\mathrm{ABI}$ sequence detection system software was used for standard curve generation and quantification.

TREC abundance was normalized to cell number by parallel nested PCR amplification of the chromosomal gene, $\beta$-globin. Outer probes 5'-GAGGGCTGAGGGTTTGAAGT-3' (forward) and 5'-TTGCCCCACAGGGCAGTAACGGCAGA-3' (reverse) were added with outer TREC primers to the first-round PCR reaction described above. As above, onetenth of the first-round product was removed in duplicate to a secondround real-time amplification performed in parallel in a manner identical to that described for TRECs, but instead using inner $\beta$-globin primers 5 'GAAGAGCCAAGGACAGGTACG-3' (forward) and 5'-CCAACCCTAGGGTGTGGCT-3' (reverse). $\beta$-Globin was quantified with the oligonucleotide probe 5'-CACAGGGTGAGGTCTAAGTGATGACAG-3'.

Data are expressed as TRECs per $10^{5}$ cells using mean values from duplicate real-time assays for both TREC and $\beta$-globin. Because there are 2 $\beta$-globin copies per cell, the TREC content was calculated as: [(mean TREC quantity / mean $\beta$-globin quantity) $\times 2$ ].

Serial dilutions of a standard plasmid control containing TREC and $\beta$-globin sequences were run in every plate to generate standard curves for quantification. Standard stocks were characterized for PCR amplicon quantities repeatedly over time and used as a quality assurance measure of all reagents for run-to-run variability. We confirmed that the nested
PCR amplification was in the linear range of the assay for both $\beta$-globin and TRECs through both rounds of amplification. Optimal conditions were determined to be $150 \mathrm{ng}$ of input DNA with 25 rounds of initial PCR followed by a 1:10 dilution of first-round PCR product into 40 rounds of real-time PCR quantification. The intra-assay and inter-assay coefficients of variation were $5.0 \%$ and $8.6 \%$, respectively.

\section{IL-7 measurement}

EDTA plasma specimens were stored at temperatures of $-80^{\circ} \mathrm{C}$ or less. Aliquots were thawed and analyzed in duplicate using a commercially available, high-sensitivity immunoassay (Quantikine HS IL-7 Immunoassay Kit; R\&D Systems).

\section{Statistics}

At the time of data analysis, all participants had completed their first year of the study in accordance with the predefined primary analysis point, with the exception of the final study participant (control arm), who enrolled substantially later than the others. Data were included for 21 study participants: $17 \mathrm{GH}$ recipients (including all GH arm participants and data from 6 observational controls who crossed over to GH) and 11 observational controls. All data for 1 of the observational controls were excluded retrospectively due to progressive laboratory test derangement and the development of lymphoma 6 months into the study. Data exclusion was otherwise performed under the following predefined circumstances: (a) all data were excluded from participants who did not complete 6 or more months in either the GH arm or observational control arm; (b) GH data were excluded if an observational control participant did not tolerate GH for at least 6 months; and (c) data from individual time points were omitted due to systemic illness, laboratory error, or technical barriers. Two particular technical barriers led to the absence of baseline PBMC TREC specimens for the first 4 study participants (causing a lower $n$ value for most PBMC TREC analyses) and the inability to quantify thymic density on CT scans after January 2006. All exclusions reflect the biological focus of this early investigation, for which a strict intention to treat analysis would be less suitable.

During the first year of the study, immunologic analyses were performed at identical intervals for both study arms. Effects of GH were estimated in 2 ways. First, changes from baseline to specific follow-up time points during the first year of the study were summarized separately for the 2 arms and compared by the nonparametric Mann-Whitney $U$ test $(P \leq 0.05$ was considered statistically significant). This parallel group analysis of changes from baseline did not take into consideration early dose reduction or discontinuation of GH and did not include GH treatment data obtained in the second year of the study, when observation arm participants crossed over to GH treatment. Second, repeated-measures regression with random subject effects was performed using the MIXED procedure in SAS (version 9.1; SAS Institute) to estimate the effects of GH treatment using data from all time points together in comprehensive models. In this analysis, effects of GH were calculated using a larger number of participants and data points, including data from observation arm recipients who received $\mathrm{GH}$ in the second year of the study. This analysis also accounted for early discontinuation of GH. Repeated-measures regression analysis estimated the effects of 1 year of GH treatment, with the exception of thymic density and circulating IGF-1 levels, for which peak effects of GH were estimated at 6 and 1 month, respectively. We also assessed the possible mediating role of GH-induced IGF-1 increases by adding an interaction term to permit differing GH effects for those with higher versus lower initial IGF-1 responses. In addition, we included interactions of $\mathrm{GH}$ effect with baseline values of IGF-1 (dichotomized at median), peak GH secretion level (dichotomized at median), and age (dichotomized at 50) to assess which patients may be most likely to benefit from GH. 
We assessed the assumption of a linear effect of cumulative time on $\mathrm{GH}$ by adding quadratic terms to the models. In cases of suspected nonlinearity, we further examined linear spline models in which the effect of time on GH could change slope at 6 months (the time of scheduled dose reduction) or 3 months. We also examined models that assumed an acute effect of GH that was already present at 1 month and remained constant thereafter. For some outcomes, we believe that relative changes are more meaningful than raw changes, so we modeled these after logarithmic transformation, with estimated effects back-transformed to estimated percentage changes. In addition, this tended to produce less violation of the assumption of normally distributed residuals in these cases. Where normality still appeared to be violated, we also note the results of the nonparametric parallel group analyses described above. Except in 1 case (PBMC TREC analysis), the nonparametric analyses provided qualitative confirmation of the regression results despite non-normality of the residuals. We did not pursue bootstrapping of the regression models because that approach might not perform well with our relatively small number of subjects. As a sensitivity analysis, we also modeled the effect of GH in terms of cumulative dose instead of cumulative time on GH. This adjusted for both planned and unplanned dose reductions but produced qualitatively similar results.

Although a number of different comparisons were examined, no formal adjustments for multiple comparisons were used. Because many analyses produced small $P$ values, and the results fit a coherent biological pattern concerning thymic function, the concern addressed by such adjustments - the possibility of falsely rejecting the global null hypothesis of no effect of GH on any outcome measure - is not an issue. In addition, we note that such adjustments would ignore the biological relationships among the different measures and treat each analysis as detracting from the other, which is exactly the opposite of the reinforcing effect each has on the other from a scientific point of view. Such adjustments would ignore the biological relationships among the different measures and the clear a priori expectations concerning the directions of the GH effects.

\section{Acknowledgments}

We thank the volunteers who participated in this study, Project Inform, and other members of the Bay Area AIDS community; the staff of the SFGH Clinical Research Center for excellent patient care; Jean-François Poulin, Christophe Kreis, Barbara Chang, Marty Bigos, Tomas Poplonski, Valerie Stepps, Amy Jo Chien, Elise Sambrano, Ethel Valiente, and the SFGH CT Radiology staff for kind assistance; Joan Lo, Kathy Mulligan, and Morrie Schambelan for endocrinology consultation; John Carroll, Teresa Roberts, Chris Goodfellow, Aaron Middlebrook, and Youngho Seo for graphics assistance; Ruth Greenblatt, Warner Greene, and the Women's HIV Interdisciplinary Network; the UCSF Core Immunology Laboratory and the UCSF-GIVI Center for AIDS Research (MO1 RR00083, P30 MH59037, and P30 AI027763). The SFGH Clinical Research Center was supported by NIH grant RR00083-44 from the National Center for Research Resources. GH and partial funding for laboratory testing was generously provided by Serono Inc. L.A. Napolitano was supported by the J. David Gladstone Institutes, by the UCSF AIDS Research Institute, and by the NIH (AI01597, AI062457). J.M. McCune is an Elizabeth Glaser Pediatric AIDS Foundation Scientist and a recipient of the Burroughs Wellcome Fund Clinical Scientist Award in Translational Research and of the NIH Director's Pioneer Award, part of the NIH Roadmap for Medical Research, through grant number DPI OD00329, and is also supported by grants from the NIH (AI43864, AI47062, and AI40312).

Received for publication May 29, 2007, and accepted in revised form January 2, 2008.

Address correspondence to: Laura A. Napolitano, Gladstone Institute of Virology and Immunology, 1650 Owens Street, San Francisco, California 94158, USA. Phone: (415) 734-4814; Fax: (415) 553-6299; E-mail: lnapolitano@gladstone.ucsf.edu.
1. Connors, M., et al. 1997. HIV induces changes in CD4+ T-cell phenotype and depletions within the CD4+ T-cell repertoire that are not immediately restored by antiviral or immune-based therapies. Nat. Med. 3:533-540.

2. Teixeira, L., et al. 2001. Poor CD4 T cell restoration after suppression of HIV-1 replication may reflect lower thymic function. AIDS. 15:1749-1756.

3. Lecossier, D., Bouchonnet, F., Schneider, P., Clavel, F., and Hance, A.J. 2001. Discordant increases in $\mathrm{CD} 4+\mathrm{T}$ cells in human immunodeficiency virusinfected patients experiencing virologic treatment failure: role of changes in thymic output and T cell death. J. Infect. Dis. 183:1009-1016.

4. Kaufmann, G.R., et al. 2002. The extent of HIV-1related immunodeficiency and age predict the long-term CD4 T lymphocyte response to potent antiretroviral therapy. AIDS. 16:359-367.

5. Kaufmann, G.R., et al. 2003. CD4 T-lymphocyte recovery in individuals with advanced HIV-1 infection receiving potent antiretroviral therapy for 4 years: the Swiss HIV Cohort Study. Arch. Intern. Med. 163:2187-2195.

6. Gandhi, R.T., et al. 2006. Effect of baseline- and treatment-related factors on immunologic recovery after initiation of antiretroviral therapy in HIV-1positive subjects: results from ACTG 384. J. Acquir. Immune Defic. Syndr. 42:426-434.

7. Gea-Banacloche, J.C., et al. 2000. Longitudinal changes in CD4+ T cell antigen receptor diversity and naive/memory cell phenotype during 9 to 26 months of antiretroviral therapy of HIV-infected patients. AIDS Res. Hum. Retroviruses. 16:1877-1886.

8. Komanduri, K.V., et al. 2001. Loss of cytomegalovi- rus-specific CD4+ $\mathrm{T}$ cell responses in human immunodeficiency virus type 1 -infected patients with high CD4+ T cell counts and recurrent retinitis. J. Infect. Dis. 183:1285-1289.

9. Gandhi, R.T., and Walker, B.D. 2002. Promises and pitfalls in the reconstitution of immunity in patients who have HIV-1 infection. Curr. Opin. Immunol. 14:487-494.

10. Klenerman, P., Wu, Y., and Phillips, R. 2002. HIV: current opinion in escapology. Curr. Opin. Microbiol. 5:408-413.

11. Douek, D.C., et al. 1998. Changes in thymic function with age and during the treatment of HIV infection. Nature. 396:690-695.

12. Poulin, J.-F., et al. 1999. Direct evidence for thymic function in adult humans. J. Exp. Med. 190:479-486.

13. Choyke, P.L., et al. 1987. Thymic atrophy and regrowth in response to chemotherapy: CT evaluation. AJR Am. J. Roentgenol. 149:269-272.

14. Kissin, C.M., Husband, J.E., Nicholas, D., and Eversman, W. 1987. Benign thymic enlargement in adults after chemotherapy: CT demonstration. Radiology. 163:67-70.

15. McCune, J.M., et al. 1998. High prevalence of thymic tissue in adults with HIV-1 infection. J. Clin. Invest. 101:2301-2308.

16. Mackall, C.L., et al. 1995. Age, thymopoiesis and CD4+ $\mathrm{T}$ lymphocyte regeneration after intensive chemotherapy. N. Engl. J. Med. 332:143.

17. Mackall, C.L., et al. 1997. Distinctions between $\mathrm{CD} 8+$ and CD4+ T-cell regenerative pathways result in prolonged $\mathrm{T}$-cell subset imbalance after intensive chemotherapy. Blood. 89:3700-3707.

18. Smith, K.Y., et al. 2000. Thymic size and lympho- cyte restoration in patients with human immunodeficiency virus infection after 48 weeks of zidovudine, lamivudine, and ritonavir therapy. J. Infect. Dis. 181:141-147.

19. Vigano, A., et al. 2000. Early immune reconstitution after potent antiretroviral therapy in HIV- infected children correlates with the increase in thymus volume. AIDS. 14:251-261.

20. Kalayjian, R.C., et al. 2005. Distinct mechanisms of $T$ cell reconstitution can be identified by estimating thymic volume in adult HIV-1 disease. J. Infect. Dis. 192:1577-1587.

21. Kolte, L., et al. 2002. Association between larger thymic size and higher thymic output in human immunodeficiency virus-infected patients receiving highly active antiretroviral therapy. J. Infect. Dis. 185:1578-1585.

22. Harris, J.M., et al. 2005. Multiparameter evaluation of human thymic function: interpretations and caveats. Clin. Immunol. 115:138-146.

23. Hakim, F.T., et al. 2005. Age-dependent incidence, time course, and consequences of thymic renewal in adults. J. Clin. Invest. 115:930-939.

24. Clark, R. 1997. The somatogenic hormones and insulin-like growth factor-1: stimulators of lymphopoiesis and immune function. Endocr. Rev. 18:157-179.

25. Knyszynski, A., Adler-Kunin, S., and Globerson, A. 1992. Effects of growth hormone on thymocyte development from progenitor cells in the bone marrow. Brain Behav. Immun. 6:327-340.

26. Kelley, K.W., Arkins, S., Liu, Q., and Dantzer, R. 1996. Growth hormone, growth factors, and hematopoiesis. Horm. Res. 45:38-45.

27. Montecino-Rodriguez, E., Clark, R, and Dorshkind, K. 
1998. Effects of insulin-like growth factor administration and bone marrow transplantation on thymopoiesis in aged mice. Endocrinology. 139:4120-4126.

28. Murphy, W.J., Durum, S.K., and Longo, D.L. 1992. Human growth hormone promotes engraftment of murine or human $\mathrm{T}$ cells in severe combined immunodeficient mice. Proc. Natl. Acad. Sci. U. S. A. 89:4481-4485.

29. Woo, J.C., Dean, G.A., Lavoy, A., Clark, R., and Moore, P.F. 1999. Investigation of recombinant human insulin-like growth factor type I in thymus regeneration in the acute stage of experimental FIV infection in juvenile cats. AIDS Res. Hum. Retroviruses. 15:1377-1388.

30. Lo, J.C., et al. 2001. The effects of recombinant human growth hormone on body composition and glucose metabolism in HIV-infected patients with fat accumulation. J. Clin. Endocrinol. Metab. 86:3480-3487.

31. Napolitano, L.A., et al. 2002. Increased thymic mass and circulating naive CD4 T cells in HIV-1- infected adults treated with growth hormone. AIDS. 16:1103-1111.

32. Rietschel, P., et al. 2001. Assessment of growth hormone dynamics in human immunodeficiency virus-related lipodystrophy. J. Clin. Endocrinol. Metab. 86:504-510.

33. Okumura, M., et al. 1993. Age-related accumulation of LFA-1 high cells in a CD8+CD45RA high T cell population. Eur. J. Immunol. 23:1057-1063.

34. Scala, E., et al. 1995. Expansion of CD11a bright cells in CD8+CD45RA+ from HIV-infected patients: a new early marker for disease progression? AIDS Res. Hum. Retroviruses. 11:1327-1333.

35. Hoflich, C., Docke, W.D., Busch, A., Kern, F., and Volk, H.D. 1998. CD45RA(bright)/CD11a(bright) CD8+ T cells: effector $\mathrm{T}$ cells. Int Immunol. 10:1837-1845.

36. Olsen, N.J., and Kovacs, W.J. 2001. Effects of androgens on T and B lymphocyte development. Immunol. Res. 23:281-288.

37. Smith, K., et al. 2004. Long-term changes in circulating CD4 T lymphocytes in virologically suppressed patients after 6 years of highly active anti- retroviral therapy. AIDS. 18:1953-1956.

38. McFarland, R.D., Douek, D.C., Koup, R.A., and Picker, L.J. 2000. Identification of a human recent thymic emigrant phenotype. Proc. Natl. Acad. Sci.U. S. A. 97:4215-4220.

39. De Rosa, S.C., Herzenberg, L.A., and Roederer, M. 2001. 11-color, 13-parameter flow cytometry: identification of human naive $T$ cells by phenotype, function, and T-cell receptor diversity. Nat. Med. 7:245-248.

40. Antov, A., Yang, L., Vig, M., Baltimore, D., and Van Parijs, L. 2003. Essential role for STAT5 signaling in $\mathrm{CD} 25+\mathrm{CD} 4+$ regulatory $\mathrm{T}$ cell homeostasis and the maintenance of self-tolerance. J. Immunol. 171:3435-3441.

41. Bernasconi, A., et al. 2006. Characterization of immunodeficiency in a patient with growth hormone insensitivity secondary to a novel STAT5b gene mutation. Pediatrics. 118:e1584-e1592.

42. Kooijman, R., and Coppens, A. 2004. Insulin-like growth factor-I stimulates IL-10 production in human T cells. J. Leukoc. Biol. 76:862-867.

43. Tian, Z.G., et al. 1998. Recombinant human growth hormone promotes hematopoietic reconstitution after syngeneic bone marrow transplantation in mice. Stem Cells. 16:193-199.

44. French, R.A., et al. 2002. Age-associated loss of bone marrow hematopoietic cells is reversed by GH and accompanies thymic reconstitution. Endocrinology. 143:690-699.

45. Carlo-Stella, C., et al. 2004. Age- and irradiationassociated loss of bone marrow hematopoietic function in mice is reversed by recombinant human growth hormone. Exp. Hematol. 32:171-178.

46. Hanley, M.B., Napolitano, L.A., and McCune, J.M. 2005. Growth hormone-induced stimulation of multilineage human hematopoiesis. Stem Cells. 23:1170-1179.

47. Min, H., Montecino-Rodriguez, E., and Dorshkind, K. 2004. Reduction in the developmental potential of intrathymic $\mathrm{T}$ cell progenitors with age. J. Immunol. 173:245-250

48. Sabharwal, P., and Varma, S. 1996. Growth hormone synthesized and secreted by human thymocytes acts via insulin-like growth factor I as an autocrine and paracrine growth factor. J. Clin. Endo- crinol. Metab. 81:2663-2669.

49. Taub, D.D., et al. 1994. Growth hormone promotes human $\mathrm{T}$ cell adhesion and migration to both human and murine matrix proteins in vitro and directly promotes xenogeneic engraftment. J. Clin. Invest. 94:293-300.

50. Smaniotto, S., et al. 2004. Growth hormone stimulates the selective trafficking of thymic CD4+CD8emigrants to peripheral lymphoid organs. Neuroimmunomodulation. 11:299-306.

51. Chu, Y.W., et al. 2004. Exogenous IL-7 increases recent thymic emigrants in peripheral lymphoid tissue without enhanced thymic function. Blood. 104:1110-1119.

52. Ribeiro-Carvalho, M.M., et al. 2007. Triiodothyronine modulates differential homing of recent thymic emigrants to peripheral lymphoid organs. Scand. J. Immunol. 66:8-16.

53 Mulligan, K., Grunfeld, C., Hellerstein, M.K., Neese, R.A., and Schambelan, M. 1993. Anabolic effects of recombinant human growth hormone in patients with wasting associated with human immunodeficiency virus infection. J. Clin. Endocrinol. Metab. 77:956-962.

54. Schambelan, M., et al. 1996. Recombinant human growth hormone in patients with HIV-associated wasting. A randomized, placebo-controlled trial. Serostim Study Group. Ann. Intern. Med. 125:873-882.

55. Engelson, E.S., et al. 2002. Effect of recombinant human growth hormone in the treatment of visceral fat accumulation in HIV infection. J. Acquir Immune Defic. Syndr. 30:379-391.

56. Moyle, G.J., et al. 2004. Growth hormone improves lean body mass, physical performance, and quality of life in subjects with HIV-associated weight loss or wasting on highly active antiretroviral therapy. J. Acquir Immune Defic. Syndr. 35:367-375.

57. Koutkia, P., Eaton, K., You, S.M., Breu, J., and Grinspoon, S. 2006. Growth hormone secretion among HIV infected patients: effects of gender, race and fat distribution. AIDS. 20:855-862.

58. Dion, M.L., et al. 2004. HIV infection rapidly induces and maintains a substantial suppression of thymocyte proliferation. Immunity. 21:757-768. 